Working Paper/Document de travail 2011-5

\title{
Private Information Flow and Price Discovery in the U.S. Treasury Market
}

by George J. Jiang and Ingrid Lo 
Bank of Canada Working Paper 2011-5

February 2011

\title{
Private Information Flow and Price Discovery in the U.S. Treasury Market
}

by

\author{
George J. Jiang ${ }^{1}$ and Ingrid Lo $^{2}$ \\ 1Department of Finance \\ Eller College of Management \\ University of Arizona \\ Tucson, Arizona 85721-0108 \\ gjiang@email.arizona.edu \\ 2Financial Markets Department \\ Bank of Canada \\ Ottawa, Ontario, Canada K1A 0G9
}

Bank of Canada working papers are theoretical or empirical works-in-progress on subjects in economics and finance. The views expressed in this paper are those of the authors. No responsibility for them should be attributed to the Bank of Canada. 


\section{Acknowledgements}

We would like to thank Asani Sarkar and participants of the 4th Central Bank Workshop on the Microstructure of Financial Markets for their helpful comments and suggestions. 


\begin{abstract}
Existing studies show that U.S. Treasury bond price changes are mainly driven by public information shocks, as manifested in macroeconomic news announcements and events. The literature also shows that heterogeneous private information contributes significantly to price discovery for U.S. Treasury securities. In this paper, we use high frequency transaction data for 2-, 5-, and 10-year Treasury notes and employ a Markov switching model to identify intraday private information flow in the U.S. Treasury market. We show that the probability of private information flow (PPIF) identified in our model effectively captures permanent price effects in U.S. Treasury securities. In addition, our results show that public information shocks and heterogeneous private information are the main factors of bond price discovery on announcement days, whereas private information and liquidity shocks play more important roles in bond price variation on non-announcement days. Most interestingly, our results show that the role of heterogeneous private information is more prominent when public information shocks are either high or low. Furthermore, we show that heterogeneous private information flow is followed by low trading volume, low total market depth and hidden depth. The pattern is more pronounced on non-announcement days.

JEL classification: G12, G14

Bank classification: Financial markets; Market structure and pricing
\end{abstract}

\title{
Résumé
}

Les études réalisées à ce jour montrent que les prix des obligations du Trésor américain réagissent surtout aux chocs d'information publique, tels les nouvelles et événements macroéconomiques. La littérature indique aussi que les flux d'information privée hétérogène jouent un rôle appréciable dans l'établissement des prix de ces titres. À l'aide de données de haute fréquence concernant les opérations sur obligations du Trésor à deux ans, à cinq ans et à dix ans, les auteurs estiment un modèle markovien à changement de régime pour isoler les flux intrajournaliers d’information privée sur le marché de ces obligations. Ils démontrent que l'estimation que donne leur modèle de la probabilité de tels flux permet de prédire efficacement les variations persistantes des prix. En outre, leurs résultats révèlent que les jours où des données macroéconomiques sont publiées, les chocs d'information publique et les flux d'information privée hétérogène sont à l'origine de l'essentiel des variations des prix des obligations, alors que les autres jours, ce sont les chocs d’information privée et de liquidité qui expliquent les variations des prix. Fait intéressant, l’information privée hétérogène se répercute davantage sur les prix quand les chocs d'information publique sont importants de même que lorsqu'ils sont négligeables. En outre, l'arrivée de flux d'information privée hétérogène est suivie d'une baisse de l'activité, de la profondeur totale et de la profondeur cachée du marché. Ce phénomène est plus marqué les jours où il n’y a aucune nouvelle macroéconomique.

Classification JEL : G12, G14

Classification de la Banque : Marchés financiers; Structure de marché et fixation des prix 


\section{Introduction}

Asset prices are subject to information shocks in financial markets and investors constantly update their valuation of assets as a result of new information arrival. Existing studies on the U.S. Treasury market show that bond price changes are mainly driven by public information shocks, as manifested in macroeconomic news announcements and events. Some noticeable studies include Fleming and Remolona (1999) and Balduzzi, Elton and Green (2001), which found that public information shocks measured by announcement surprise have a significant effect on the price of U.S. treasury instruments. In addition, Fleming and Remolona (1997) find that the 25 largest price changes of the on-the-run 5year note are all associated with news announcements. Similar findings are documented in Bollerslev, Cai, and Song (2000) over a later sample period.

Recent literature further documents that private information flow also contributes significantly to price discovery in the U.S. Treasury market. Green (2004) finds that post-announcement order flow has a higher information content in the 5-year Treasury note relative to non-announcement days. Pasquariello and Vega (2007) find that private information manifests on days with larger belief dispersion. Menkveld, Sarkar and van der Wel (2008) provide similar findings for 30-year Treasury bond futures. Brandt and Kavajecz (2004) find that order flow imbalances account for up to $26 \%$ of the day-to-day variation in yields on days without major macroeconomic announcements. All studies point out that order flow affects the price discovery process in the Treasury market because order flow aggregates heterogeneous private information.

The focus of this paper is to extend existing studies and examine intraday private information flow in the U.S. Treasury market on both announcement and non-announcement days. We argue that analysis of information arrival at a high frequency is important and crucial in the U.S. Treasury market. This is because information disseminates quickly into bond prices. For instance, Green (2004) points out that private information dissipates within the first fifteen minutes after announcements. In addition, the Treasury market offers an ideal setting to disentangle public information flow versus private information flow. The interpretation of private information in our study is similar to that in Brandt and Kavajecz (2004). That is, it can take in two different forms. One form of private information stems from hetero- 
geneous interpretation of public information. In particular, some investors may have superior ability in interpreting public information due to experience or, for example, the use of more sophisticated models (Brandt and Kajeck (2004)). The other form refers to certain investors' access to exclusive sources of information. An example of such private information is that dealers may have private access to client order flow and thus gain information exclusive to other investors. As shown in Evans (2002) and Evans and Lyons (2002) using data in foreign exchange markets, such information has predictive power of short-term price movements. Focusing on announcement days, we examine how heterogeneous private information among investors interacts with public information flow in driving bond price discovery. Focusing on non-announcement days, we examine how private information exclusive to certain group of investors drives the price discovery process of U.S. Treasury securities. In both cases, heterogeneous private expectations are aggregated through trading into a market price in an imperfect informational environment. Finally, the Treasury market provides a clean setting to examine heterogenous private information across market participants. With no cash flow risk, different valuation of Treasury securities across market participants is primarily due to heterogeneous expectations.

One challenge of our study is that compared to public information flow in the Treasury market, which generally coincides with news announcements, private information flow is not directly observed. In this paper, we use the impact of order flow on bond prices to infer private information flow. For example, Brandt and Kajeck (2004) argue that order flow impact effectively captures heterogeneous information flow in the U.S. Treasury market. Empirically, Green (2004), Pasquariello and Vega (2007) use order flow impact to proxy for the level of information asymmetry on announcement versus nonannouncement days in the Treasury market. Loke and Onayev (2007) also find state-varying level of order flow impact in the S\&P futures market. Using information from order flow impact, we specify a Markov switching model to identify private information flow. Using high frequency transaction data for the 2-, 5-, and 10-year Treasury notes, we obtain 5-minute estimates of the probability of private information flow (PPIF hereafter). In this aspect, our model can be viewed as an extension of the existing PIN model by Easley et al. (2002) and Li et al. (2009).

The data used in our study is obtained from the BrokerTec electronic limit order book platform on 
which secondary interdealer trading occurs. It contains not only tick-by-tick information on transaction and market quotes but also information of the entire limit order book for the on-the-run 2-year, 5-year, and 10-year notes. This allows us to examine the effect of heterogeneous private information in high frequency. The detailed information on the limit order book also allows us to examine how liquidity dynamics interact with private information. A novel aspect of our paper is that we examine how liquidity reacts to information uncertainty. Given that the timing and the context of information arrival is unknown on non-announcement days, we look at how trading activities and placement of limit orders differs from that on announcement days. Data on announcements comes from Bloomberg and includes date, time and values for expected and actual announcements. Since surveys of market participants provide ex ante expectations of major economic announcements, measures of announcement surprises or unexpected information shocks can be constructed.

Our results show that PPIF is higher for longer maturity bonds, and higher on announcement days than on non-announcement days. The finding is consistent with Brandt and Kavajecz (2004) that price discovery manifests in less liquid markets. In addition, on announcement days, PPIF coincides with public information shocks as measured by announcement times. This is consistent with Green(2004) finding that the role of private information is hihger at and after announcements.

One of the key questions is whether the PPIF identified using the Markov switching model indeed captures information effect on bond prices. To answer this question, we use permanent price impact as a yardstick to measure the information content of PPIF. The main premise of our analysis is that if PPIF captures private information flow then we should expect bond price changes associated with high PPIF to have permanent impact whereas bond price changes associated with low PPIF to have only transitory effects. We employ both the nonparametric method in Kaniel and Liu (2006) and a probit model to test the hypothesis. In the probit model, we explicitly control for the effect of public information shocks as measured by announcement surprises. The results of both the nonparametric test and the probit model show that bond price changes associated with high PPIF in fact exhibit significant permanent price impact over 30 minutes, 1-hour and 1-day horizons on both announcement and nonannouncement days. Although the impact of PPIF drops overtime, it remains significant up to the 1-day 
interval. In particular, the results on non-announcement days provide evidence that the information content captured by PPIF is largely private in nature.

We then examine how much explanatory power PPIF has for price bond variation by regressing bond price volatility against PPIF and other control variables. For non-announcement days, the regression uses 15-minute realized volatility over the entire day, whereas for announcement days the regressions are performed over the two 15-minute intervals after announcement time. For both announcement and non-announcement days, we include liquidity shocks in the regression, whereas for announcement days we also include major announcement surprises to control for the effect of public information shocks. Consistent with existing studies, our results show that bond price variation is positively related to public information shocks. Liquidity shocks have a more significant effect on price variation on nonannouncement days. Most importantly, for both announcement and non-announcement days, PPIF has significant explanatory power for bond variance, even after controlling for public information shocks and liquidity shocks. Across maturities, there is a higher sensitivity of bond price variation with respect to PPIF changes. This is consistent with the notion that heterogeneous private information plays a more important role in markets with less liquidity. Comparing announcement days with non-announcement days, PPIF actually plays a more important role on announcement days. This is evidence that investors hold heterogeneous beliefs of the public information and thus form divergent expectations about future economic conditions (Green (2004)). As such, the information content of public news announcements is not impounded into bond prices instantaneously. Instead, it takes trading among investors to discover new equilibrium prices. The results on announcement days further show that the sensitivity of bond price variation to PPIF change decreases during the post-announcement period.

To further examine how heterogeneous private information interacts with public information shocks in driving the price discovery process on announcement days, we sort all announcements into terciles according to the standardized announcement surprises. In each tercile, we calculate the average PPIF during the post-announcement period. Interestingly, we observe a rather consistent U pattern in PPIF. That is, for announcements with large or small information shocks there is a higher level of private information flow in the market. On the other hand, when announcement surprise is at medium level, 
the level of private information flow is low. Our conjecture is that when announcement surprise is at a medium level, there is less disagreement or divergent interpretation of the information among investors. When the information shock is large then there is likely more disagreement and diverse interpretation of the information among investors. Interestingly, when the information shock is small, the role of public information in the price discovery is relatively small and heterogeneous private information plays an important role driving bond prices. To confirm our conjecture, we also compute realized volatility in the post-announcement period for each of the terciles based on announcement surprises. The return volatility exhibits a similar $U$ pattern as the PPIF. This is an indication that bond prices converge relatively slower when public information shocks are either high or low.

Finally, we look at how market liquidity is related to information arrival and how it evolves subsequently. We sort the liquidity measures into terciles according to PPIF and look at how they evolve in the subsequent two hours interval. The results show that a higher level of private information is associated with lower trading volume, lower depth and lower hidden depth concurrently and in the subsequent two hour horizon, both at the best quote and on the whole book. The difference is more pronounced on non-announcement days. It suggests that market participants refrain from trading and posting new limit orders in the presence of private information. However, information arrival on non-announcement days affects spread differently. Spread in the highest PPIF group on announcement days reverts subsequently after information arrival whereas spread on non-announcement days remains at elevated levels for the next two hours. Our findings suggests market participants refrain from posting aggressive quotes for prolonged period when the nature of information arrival is less clear on non-announcement days.

The rest of paper is structured as follows. Section II describes the data used in our study and the Markov switching model. Section III present main empirical results. Section V concludes.

\section{Data and Model}

\section{A. Data}

The U.S. Treasury securities data are obtained from BrokerTec, an interdealer electronic trading platform in the secondary wholesale U.S. Treasury securities market. Prior to 1999, the majority of in- 
terdealer trading of U.S. Treasuries occurred through interdealer brokers. Since 1999, the majority of trading of on-the-run Treasuries has migrated to two electronic platforms, the eSpeed and the BrokerTec. Mizrach and Neely (2008) and Fleming and Mizrach (2008) provide detailed descriptions of the migration to electronic platform and price discovery on the BrokerTec platform. According to Barclay, Hendershott and Kotz (2006), the electronic market shares for the 2-, 5- and 10-year bond are, respectively, $75.2 \%, 83.5 \%$ and $84.5 \%$ during the period of January 2001 to November 2002. By the end of 2004, the majority of secondary interdealer trading was through electronic platforms with over $95 \%$ of the trading of active issues on electronic platforms. ${ }^{1}$

BrokerTec is more active in the trading of 2-, 5- and 10-year Treasury notes than eSpeed. The BrokerTec platform functions as a limit order book. Traders can submit limit orders, i.e., orders that specify both price and quantity posted on the book, or they can submit marketable limit orders, i.e., orders with a price better than or equal to the best price on the opposite side of the market, to ensure immediate execution. Limit order submitters can post "iceburg" orders, where only part of their order is visible to the market and the remaining part is hidden. All orders on the book except the hidden part of the orders are observed by market participants. The orders remain in the market until matched, deleted, inactivated, loss of connectivity, or the market closes. The market operates more than 22 hours a day from Monday to Friday. After the market closes at 5:30 p.m. eastern time (ET), it opens again at 7:00 p.m. ET.

The sample period is from January 2004 to June 2007. Days with early closing before public holidays are excluded since liquidity is typically low for these days. The dataset consists of over 700.8 million observations and 16.9 million transactions. The dataset contains the tick-by-tick observations of transactions, order submissions, and order cancelations. It includes the time stamp of transactions, quotes, the quantity entered and deleted, the side of the market and, in the case of a transaction, an aggressor indicator. Fleming and Mizrach (2008) provide a more detailed description of the microstructure of BrokerTec platform. We use data from 7:30 a.m. ET to 5:00 p.m. ET since trading is more active during this time interval. This interval also contains all pre-scheduled U.S. news announcements, and

\footnotetext{
${ }^{1}$ See "Speech to the Bond Market Association", December 8, 2004 by Michael Spencer, founder and chief executive of ICAP PLC.
} 
it provides us with 9.5 hours of trading and 114 five-minute return observations each day.

Table I provides descriptive statistics of the data. Spreads are defined both in relative terms and in ticks. Relative spread is defined as

$$
\text { relative spread }=(\text { best bid price }- \text { best ask price }) / \text { mid-quote }
$$

and measured at the end of each 5-minute interval and averaged over the trading day. Tick spread is defined similarly. The tick size of the 2-year and 5-year note is $1 / 128$, whereas that of the 10 -year note is $1 / 64$. Daily return volatility is calculated as the square-root of the sum of squared log mid-quote difference sampled at 5-minute intervals

$$
\text { return volatility }=\left(\sum_{i=1}^{114}\left(\ln p_{i}-\ln p_{i-1}\right)^{2}\right)^{1 / 2}
$$

where the mid-quote is defined as $p_{i}=($ best bid price + best ask price $) / 2$. The average (hidden) depth (in millions) at the best bid/ask is the total (hidden) observed depth at the best price on both the bid and ask side of the market measured at the end of each 5-minute interval and averaged over the trading day. The average depth and average hidden depth in the entire order book are defined similarly.

BrokerTec is a highly liquid platform over our sample period. As shown in Table I, the relative spread is smallest for the 2-year note with a sample mean of $0.0109 \%$, followed by the 10 -year note $(0.0118 \%)$ and 5-year note $(0.0126 \%)$. Trading volume is highest for the 2-year note $(\$ 25.86$ billion per day), followed by the 5-year note ( $\$ 23.43$ billion per day), and 10 -year note $(\$ 20.70$ billion per day). Intraday return volatility generally increases with maturity, possibly due to higher bid-ask spread and less market depth at longer maturities. The 2-year note has the deepest book, both at the best quote (\$547.09 million) and the entire book (\$4,092 million). Hidden depth is low in general, and hidden orders at the best quote are less than $5 \%$ of the observed depth at the best quote for all three maturities.

Figure 1 presents the intra-day activities in the 2-year note. The intraday patterns for other bonds are similar and thus not reported for brevity. Consistent with the findings in Fleming (1997), trading volume peaks first in the 8:30 to 10:00 ET interval and goes up again from 13:00 to 14:00 ET. These two intervals overlap with major macroeconomic announcements. Relative spread is higher at the beginning (before 8:30 ET)) and the end of the trading day (after 16:00 ET). The depth at the best price is thinner 
before 8:30 ET and after 15:00 ET. For the rest of the day, the book is on average over \$600 million. The level of hidden depth is higher at noon and it goes up again after 15:00 ET. This finding suggests that market participants hide more of their orders when there is less total depth in the market.

Data on macroeconomic news announcements and the survey of market participants come from Bloomberg and Briefing.com's economic calendar. Balduzzi, Elton and Green (2001) show that professional forecasts based on surveys are neither biased nor stale. Announcement days are defined as days in which one or more announcement took place. To ensure the list of announcements is comprehensive, we start with the 25 announcements from Pasquariello and Vega (2007). We then include 7 additional economic announcements: FOMC minutes, ISM service, NY Empire State Index, Chicago PMI, Existing Home Sales, Philadelphia Fed Index, and ADP National Employment Report. In addition to pre-scheduled news announcements, we collect the auction result release times for 2-year, 5-year and 10-year notes. Lastly, we collect the release of the testimony of Semiannual Monetary Policy Report and Economic Outlook. The full list of announcements can be found in Table II. Following Balduzzi, Elton and Green (2001) and Andersen, Bollerslev, Diebold and Vega (2007), the standardized announcement surprise is defined as

$$
S U R_{j t}=\frac{A_{j t}-E_{j t}}{\hat{\sigma}_{j}}
$$

where $A_{j t}$ is the actual announcement, $E_{j t}$ is the median forecast for news $j$ on day $t$, and $\hat{\sigma}_{j}$ is the standard deviation of $A_{j t}-E_{j t}, t=1,2, \cdots, T$.

\section{B. The Markov Switching Model}

In this section, we present the Markov switching model used to identify private information flow in the Treasury market. Information arrival is modeled through state-varying order flow impact. Recent literature documented that order flow aggregates heterogeneous private information into the price discovery process. Thus the impact of order flow measures the extent of private information incorporated into price. Furthermore, there is evidence that the impact of order flow is state-varying. Brandt and Kavajecz (2004) find that the impact of order flow on yields is strongest when liquidity is low. Green (2004) finds that order flow has a greater impact on bond price when the price change at announcement 
is large. Pasquariello and Vega (2007) find that order flow impact is strongest when dispersion of belief among market participants are high. Loke and Onayev (2007) also find a state-varying level of order flow impact in the S\&P futures market.

One common focus of the above studies is the comparison of the impact of order flow in different market conditions, e.g. liquid versus illiquid market, announcement versus non-announcement days, etc. As such, the findings in existing studies are generally aggregated over different market conditions. This could be the reason that findings documented in different studies sometimes appear to be conflicting with each other. For example, Green (2004) identifies greater informational role of order flow impact when the market is very liquid, while on the other hand, Brandt and Kavajecz find the opposite.

In this paper, we deal with the latent nature of private information flow using a Markov switching model. The two states of our Markov switching model represent, respectively, a state with low order flow impact (State 1) and a state with high order flow impact (State 2). The transition probabilities are defined as

$$
\begin{aligned}
& p\left(p_{t} \in S_{1} \mid p_{t-1} \in S_{1}\right)=p_{11} \\
& p\left(p_{t} \in S_{2} \mid p_{t-1} \in S_{1}\right)=1-p_{11} \\
& p\left(p_{t} \in S_{1} \mid p_{t-1} \in S_{2}\right)=1-p_{22} \\
& p\left(p_{t} \in S_{2} \mid p_{t-1} \in S_{2}\right)=p_{22}
\end{aligned}
$$

The higher order flow impact state proxies for the existence of private information. We also incorporate the standardized surprise of important news announcements to control for the public information shock on the dynamics of return and volatility. More specifically,

$$
\Delta p_{t}=\rho \Delta p_{t-1}+\mu+\mu_{P P I F} * S_{t}+\beta_{O F} O F_{t}+\beta_{O F, P P I F} * O F_{t} * S_{t}+\sum_{j=1}^{N} \gamma_{j} S U R_{j t}+\varepsilon_{t}
$$

where $O F_{t}$ is order flow measured as the number of bid trades minus the number of ask trades, and $\varepsilon_{t} \sim N\left(0, \sigma+\sum_{j=1}^{N} \theta_{j}\left|S u r_{j, t}\right|\right)$, i.e., volatility is also affected by public information shocks. In this model, return is affected by both public information shocks and private information arrival via the impact of order flow, where $\beta_{O F, P P I F}$ captures the additional effect of private information. If order flow impact is larger when private information arrives as found in Brandt and Kavajecz (2004), Green 
(2004), Pasquariello and Vega (2007) and and Menkveld et al. (2008), then $\beta_{O F, P P I F}$ should be significantly positive. Another implication from the model is about how efficiently the market incorporates private information flow. If private information is incorporated quickly into asset prices, then the transitional probability from information arrival state to information arrival state, $p_{22}$, should be lower than the transitional probability from no informed trading to no informed trading $p_{11}$. This is because information dissipates quickly in an efficient market and so informed trading is less likely to continue in the next period.

To ensure that our result is not driven by the intraday seasonality in volatility as evident in Figure 1, we diurnally adjust returns by

$$
\Delta p_{t}=\frac{\Delta \tilde{p}_{t, j}}{\sigma_{j}^{a d j}}
$$

where $\Delta \tilde{p_{t, j}}$ is the raw unadjusted log return (times 1,000) within the $j$ th 30 -minute interval within the trading day ${ }^{2}$ and $\sigma_{j}^{\text {adj }}$ is the intraday adjustment factor. We calculate the adjustment for intraday trading effect using only the data from non-announcement days. That is, $\sigma_{j}^{a d j}$ is the average realized volatility within the $j$ interval over all non-announcement days divided by the average realized daily volatility.

Using estimates of the Markov switching model, we calculate the probability of private information arrival (PPIF) implied by the Markov switching model. The conditional probability of private information arrival is given by $P P I F_{t}=\left(P_{j} \in S_{2} \mid \Delta p_{j}, \Delta p_{j-1}\right)$ and is calculated using the EM algorithm as described in Hamilton (1990).

\section{Empirical Results}

\section{A. Estimation Results}

We estimate Markov switching models as defined in (??) using data for the 2-, 5- and 10-year treasury notes. Since we have more than 30 pre-scheduled announcements, it is infeasible to include all of them in the estimation of the model. Our choice of announcements is based on findings in previous literature. More specifically, we first include 7 "influential announcements" from Pasquariello and Vega (2007): Change in Nonfarm Payrolls (Nonfarm), Consumer Confidence Index (C.Confi), ISM Index (ISM),

\footnotetext{
${ }^{2}$ We divide the trading day into thirteen 30 -minute intervals.
} 
Initial Jobless Claims (Ini.Jobls.), Leasing Indicators (Leading), New Home Sales (NewHome) and Retail Sales (Retail). Given these announcements, we add announcements to the model one-by-one sequentially. An announcements is kept in the model if it significantly increases model fit, as measured by the increase in likelihood function. Five additional announcements are included as a result: CPI, Durable Goods (Dur), GDP advance (GDPadv), PPI and FOMC ${ }^{3}$.

Table 3 reports the estimation results. The estimates of $\beta_{O F, P P I F}$ are significantly positive for all maturities. Another interesting observation is that the estimates order flow impact increases with maturities. This holds for both the states with low and high impact of order flow. Given that the depth of both the 5-year and the 10-year notes is one-fifth that of the 2-year note, it is therefore easier for a transaction of a given size to walk up/down the book and create a larger price impact. Thus our findings are consistent with Brandt and Kavajecz (2004) finding that private information manifests in a less liquid market.

Turning to transitional probability, the results show that the transitional probability of remaining in State $2\left(p_{22}\right)$, the high order flow impact state, is lower than the transitional probability of remaining in State $1\left(p_{11}\right)$, low order flow impact state for all maturities. The result implies that it is less likely that private information persists in a market and that it dissipates quickly in an efficient market. Another finding is that $p_{22}$ increases in maturity. This means the private information arrival state is more likely to persist in longer maturity notes. The finding is consistent with the fact that price formation or resolution of information uncertainty is slower in the less liquid 5- and 10-year notes markets.

Table 4 reports the summary statistics of PPIF estimates. We found that the sample mean of PPIF increases with maturities in all trading days, announcement days and non-announcement days. The finding is consistent with Brandt and Kavajecz (2004) that price discovery manifest in less liquid markets. The sample mean of PPIF is higher on announcement days than on non-announcement days. The finding is consistent with existing empirical research on the Treasury market, such as Green (2004), and Menkveld et al. (2008), in that private information is more prominent during announcement days than on non-announcement days in the Treasury market. This is because prescheduled announcements

\footnotetext{
${ }^{3}$ As there is no announcement surprise in FOMC during the sample period, we set a dummy variable equal to one if FOMC occurs on a trading day and zero otherwise
} 
represents the majority of information arrival and traders trade on their heterogeneous interpretation of public announcements. Nevertheless, the median PPIF of non-announcement days is similar in magnitude to that of announcement days. Thus private information on non-announcement days plays an important role in the price discovery process as well.

Figure 2 plots the intraday patterns of PPIF based on the Markov switching model for the 2-year note. The plots are similar for other maturities. PPIF peaks around pre-scheduled macroeconomic news announcement times, such as 8:30 AM and 10:00 AM. Consistent with the empirical evidence in Green (2004), Pasquariello and Vega (2007) and Menkveld et al. (2008) that private information is more evident around announcements, this finding offers initial evidence that the PPIF estimate captures the arrival of private information in the Treasury notes market. On days without announcements, the intraday pattern of information arrival is less distinctive. This is consistent with the intuition that private information could arrive at any time across the trading day. Nonetheless the PPIF measure is higher during mid-day and at the end of the trading day. The finding is not due to intraday seasonality as it has already been removed from return and volatility dynamics. Our conjecture is that during these times, particularly at the end of the trading day, it is more difficult to unwind positions. Thus dealers are more cautious of the possibility of trading against informed traders, resulting in less depth placed in the market. This in turn leads to a less liquid market and thus private information has a larger impact.

\section{B. Private Information Flow and Price Persistence}

In this section, we use price persistence as our main yardstick to examine whether the PPIF measures from the Markov switching model actually capture private information arrival. If PPIF is truly informative, then a high PPIF should have long-lasting price persistence because information arrival should have a permanent effect on price. Otherwise, there should be price reversal.

We first use a nonparametric test based on Kaniel and Liu (2006) to examine price persistence. A 5-minute interval is defined as having high (low) probability of private information arrival (hereafter high (low) PPIF) if the PPIF estimate is above (below) the 20th (80th) percentile of the PPIF estimates over the previous 5 days. If PPIF contains private information, the future return $R_{[k-1, k+j]}=\ln P_{k+j}-$ 
$\ln P_{k-1}$ should remain in the same direction as $R_{[k-1, k]}$ when PPIF is high. The opposite should hold for the case of low PPIF: price change should reverse if it is not due to information arrival.

More specifically, let $n_{P P I F}$ be the number of same direction mid-quotes in the 30-minutes, 1-hour and 1-day following a high PPIF. Further, let $P_{\text {highPPIF }}$ be the fraction of times that PPIF is high and $n$ be the total number of quotes in the same direction in the 30-minutes, 1-hour and 1-day following all PPIF $F_{t, k}$. Under the null hypothesis $H_{0}$ of equal informativeness under high PPIF and other PPIF, the probability that out of these $n$ quote revisions $n_{P P I F}$ or more are preceded by a significant PPIF is approximated by

$$
1-N\left[\frac{n_{P P I F}-n \cdot P_{h i g h P I A}}{\sqrt{n \cdot P_{h i g h P I A}\left(1-P_{h i g h P I A}\right)}}\right]
$$

where $N$ is the standard normal cumulative distribution function. We conduct the test on the overall sample, on announcement days and on non-announcement days. The case for low PPIF is defined in a similar way. Since there may be other announcements in the interim for a 1 day interval, we also control for the robustness of the test by including only observations without significant announcements ${ }^{4}$ of Nonfarm Payroll, Consumer Confidence Index, ISM Index, Initial Jobless Claims, Leading Indicators, New Home Sales and Retail Sales in the next day interval. The results are qualitatively similar and are not shown for brevity purpose.

The results of the model are reported in Table 5. The first set of columns shows the p-values of the non-parametric test of price persistence following high PPIF on all trading days, on announcement days and on non-announcement days, respectively. In all three maturities, the null hypothesis of equal informativeness is rejected at the $1 \%$ level for the 30-minute, 1-hour and 1-day horizon. The results hold for all trading days, announcement days and non-announcement days. Thus the results indicates that PPIF is informative - a high PPIF is related to informed trading and leads to permanent price change. Contrary to the results in the high PPIF group, the null hypothesis of equal informativeness in the low PPIF group is not rejected in all maturities. The result indicates that a low PPIF is associated with the absence of private information arrival and thus price change is less likely to persist as a result.

One disadvantage of the nonparametric test is that a cutoff criteria has to be imposed to define

\footnotetext{
${ }^{4}$ We define significant announcements with standardized surprise larger than or equal to 1
} 
the high and low PPIF group. We next look at whether a larger PPIF measure is more likely to be related to a same direction future price change via a probit regression. More specifically, we create a dummy variable $P\left(\right.$ state $\left._{t+h}\right)$. It is equal to 1 if $R_{[t-1, t+h]}$ is in the same direction as $R_{[t-1, t]}$, where $h$ is set equal to a 30-minute, 1-hour or 1-day horizon. If PPIF measures are informative for future price change, the likelihood of observing same direction price change increases with PPIF and PPIF should be significantly positive in the probit regression. We test this prediction by running probit regressions, where the dependent variable is $P\left(\right.$ state $\left._{t+h}\right)$ and the explanatory variable is PPIF. More specifically, the regression on non-announcement days is specified as

$$
P\left(\text { state }_{t+h} \mid \text { non - announcementdays }\right)=f\left(\alpha+\beta_{P P I F} P P I F_{t}\right)
$$

We also include announcement surprises as control variables on announcement days. The regression on announcement days is specified as

$$
P\left(\text { state }_{t+h} \mid \text { announcementdays }\right)=f\left(\alpha+\beta_{P P I F} P P I F_{t}+\sum_{j=1}^{N} \gamma_{j} S U R_{j, t}\right)
$$

In terms of predictive power of the PPIF measures, results in Table 6 are consistent with the findings in the nonparametric model. The PPIF measures are all positive and statistically significant for 30minute, 1-hour and 1-day horizons. This holds for all trading days, announcement days, and nonannouncement days. This implies that a higher PPIF is related to a higher likelihood of a same direction price change. That is, PPIF captures private information arrival in the Treasury market. We also find evidence that the predictive power of the PPIF measures drops over time. The predictive power of PPIF is strongest at the 30-minute horizon. But the magnitude of the coefficient capturing the impact of PPIF drops successively as we move to the 1-hour and 1-day horizons for both announcement and non-announcement days. Nevertheless the impact of PPIF remains significant over the 1-day interval.

\section{Private Information Flow and Bond Price Variation}

In this section, we examine how much explanatory power PPIF has for bond price variation by regressing bond price volatility against PPIF and other control variables. The idea that volatility is related to information arrival dates back to Clark (1973). Ross (1989) further shows that price volatility is 
perfectly correlated with information arrival in an arbitrage free economy. Other related work includes Andersen (1996), Andersen and Bollerslev (1997). In these models, there is no distinction between public or private information. Changes in volatility could be due to either type of information. Examining the explanatory power of PPIF allow us to explore whether private information affects volatility. If volatility only captures public but not private information, then the PPIF measure should not be significant.

On non-announcement days, the regression is performed using 15-minute realized volatility over the entire day. The explanatory variables include PPIF and liquidity shocks variables

$$
\begin{aligned}
R V_{\tau}= & \alpha+\beta_{P P I F} \overline{P P I F}_{\tau} \\
& +\beta_{\text {sprdshk }} s p r d s h k_{\tau}+\beta_{t r d s h k} t r d d s h k_{\tau}+\beta_{d e p s h k} d e p d s h k_{\tau}+\varepsilon_{\tau}
\end{aligned}
$$

where realized volatiity, $R V_{\tau}$, is constructed from $\ln$ return over one-minute intervals and is defined as

$$
R V_{\tau}=\left(\sum_{i=1}^{15}\left(\ln p_{\tau, i}-\ln p_{\tau, i-1}\right)^{2}\right)^{1 / 2}
$$

and $\overline{P P I F}$ is PPIF averaged over the corresponding 15 minute interval. The standardized shock to spread $\left(\operatorname{sprdsh} k_{t}\right)$ is defined as:

$$
\operatorname{sprdsh} k_{\tau}=\frac{\overline{\text { spread }}_{\tau}-\frac{1}{5} \sum_{j=1}^{5} \overline{\text { spread }}_{\tau, j}}{\sigma_{\text {spread }}},
$$

where $\overline{\operatorname{spread}_{\tau}}$ is the average spread during the 15 -minute interval and $\overline{\text { spread }_{t, j}}$ is the spread within the same 15-minute interval during the past five most recent non-announcement days. The standardized shock to overall market depth, depshk, and trading volume, $\operatorname{trdsh} k$, are defined similarly.

On announcement days, the regressions are performed over the two 15-minute intervals after the announcement time. In addition to liquidity shocks, we also include major announcement surprises to control for the effect of public information shocks. The purpose is to examine what role private information plays after public information shocks. The regression we estimate is specified as

$$
\begin{aligned}
& R V_{\tau}=\alpha+\beta_{P P I F} \overline{P P I F}_{\tau}+\sum_{j=1}^{N} \gamma_{j}\left|S U R_{j, t}\right|
\end{aligned}
$$

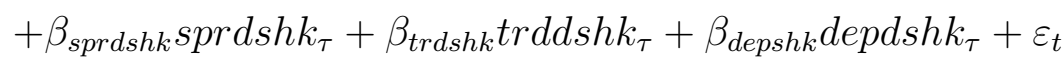


The results provide insights into the role played by private information, public information and liquidity in price variation. Consistent with existing studies, our results (see Table 7) show that volatility is positively related with public information shocks. For all three maturities we examine, realized volatility significantly increases with respect to announcement surprises in Change in Nonfarm Payroll, CPI and GDP. The effect is significant for the two 15-minute intervals after announcement time. Liquidity shocks, on the other hand, play a marginal role immediately after an announcement. The three liquidity shock measures contribute to less than $1 \%$ of the variation in volatility immediately after announcements whereas their contribution rises to more than $15 \%$ of the variation in volatility in the second 15-minute interval after announcements.

Most importantly, for both announcement and non-announcement days, PPIF has significant explanatory power for bond variance, even after controlling for public information and liquidity shocks. Moreover, there is a higher sensitivity of bond price variation with respect to PPIF changes in the 5and 10-year notes on both announcement days and non-announcement days. This is consistent with the notion that heterogeneous private information plays a more important role in markets with less liquidity. The results on announcement days further show that the sensitivity of bond price variation to PPIF change decreases during the post-announcement period. This is consistent with Green (2004) finding that the private informational role of trading is highest immediately after an announcement. Comparing announcement days with non-announcement days, PPIF plays a more important role in volatility immediately after announcement. This is evidence of how important investor interpretation of public information is to the price discovery process. Nevertheless, PPIF remains significantly positive on nonannouncement days and the magnitude of coefficients is similar to the second 15-minute interval after announcements.

\section{Public Information Shocks and Heterogeneous Private Information}

In this section, we further examine how heterogeneous private information interacts with public information shocks in driving the price discovery process on announcement days. We sort all announcements into terciles according to the standardized announcement surprises. In each tercile, we calculate 
the average PPIF during the post-announcement period.

The second column in Table 8 shows the PPIF sample mean of all news announcements (Panel A) and a selection of individual news announcements (Panel B to Panel E) over two 15-minute intervals after announcement time. Interestingly, we observe a rather consistent U pattern in PPIF. That is, for announcements with large or small information shocks there is a higher level of private information flow in the market. The $\mathrm{U}$ pattern holds for both 15-minute intervals after announcements, though the level of PPIF in the second 15-minute interval is lower. On the other hand, when announcement surprise is at a medium level, the level of private information flow is also low. Our conjecture is that when announcement surprise is at medium level, there is less disagreement or divergent interpretation of the information among investors. When the information shock is large then there is likely more disagreement and diverse interpretation of the information among investors. Interestingly, when the public information shock is small, the role of public information in the price discovery is relatively small and heterogeneous private information plays an important role driving bond prices. We also find that the level of private information varies among announcements. The PPIF level after the Change in Nonfarm Payroll remains consistently higher than, say, Consumer Confidence in the subsequent 30 minutes interval, though the absolute surprise level is similar across the two announcements

To confirm our conjecture, we also compute realized volatility and bid-ask spread in the postannouncement period for each of the terciles based on announcement surprises. The third and the last column in Table 8 shows the result on post-announcement realized volatility and bid-ask spread. The return volatility and spread exhibit a similar U pattern as the PPIF. Similar to the patterns of PPIF, realized volatility (spread) is higher (wider) with large or small information shocks for both 15-minute intervals after announcements. This is an indication that bond prices converge relatively slower when public information shocks are either high or low.

\section{E. Private Information Flow and Market Liquidity}

We next look at how liquidity is related to private information arrival and how it evolves subsequently. We offer two novel contributions to the literature. The first is that we examine liquidity after private 
information arrival on non-announcement days. The issue is important because the nature of information arrival on non-announcement days is different in that both the timing and the context of private information arrival is more uncertain than on non-announcement days. This uncertainty could potential impact the liquidity of the market. Our second contribution is that we consider a more complete set of liquidity measures. In addition to trading volume and bid-ask spread, we examine how the market depth at the best quotes, overall depth and hidden depth of the limit order book evolves after private information arrival. This is particularly important given the growing importance of limit order platforms in equity, foreign exchange and Treasury markets.

We sort liquidity measures - trading volume, depth at the best quotes, overall depth, hidden depth at the best quote, overall hidden depth and spread- according to their associated PPIF estimates at each 5-minute interval into 3 terciles and examine how liquidity measures are related to private information concurrently and in the subsequent two hour interval. On announcement days, we sort the PPIF for at announcements times. On non-announcement days, we sort PPIF from 8:00 ETS to 15:00 ETS during the trading day. For each group, we report the sample mean depth at the best quotes ( $D E P 0)$, overall depth (DEPALL), hidden depth at the best quotes (HID0), overall hidden depth $(H I D A L L)$, trading volume (TRDQN), and relative bid-ask spread (SPREAD) concurrently. We then calculate the averages of these variables within each group in the next 30-minutes interval, 30 - to 60- minutes interval, 60- to 90- minutes interval, and 90- to 120- minutes interval.

Table 9 reports the sorting results for the 2-, 5- and 10-year notes. Trading volume at announcement times is higher than that on non-announcement days, which is consistent with existing empirical findings. Most interestingly, our findings for trading volume offer a partial explanation for the contrasting finding in Green (2004) and Brandt and Kavajecz (2004): Green (2004) found that information asymmetry increases during announcements when trading volume is high in the 5-year note while Brandt and Kavajecz (2004) found that level of information asymmetry increases when market liquidity is low. We indeed find that trading volume is decreasing with PPIF on non-announcement days. At announcement times, trading volume varies with PPIF in a U-shape pattern in the 5-year and 10-year notes. Trading volume is high in both the low PPIF group and the high PPIF group. It seems that when information 
asymmetry is high and the context of private information is uncertain on non-announcement days, market participants refrain from trading in the market and thus high information asymmetry is associated with a lower level of trading volume. But when the context of information is known at announcements, traders who are confident about their interpretation of information enters the market to trade and thus high information asymmetry is also associated with a higher level of trading volume.

Next we examine how market depth reacts to private information arrival. This issue has largely been unexplored in the literature because information on depth was generally not available before the transition to the electronic limit order book in the Treasury market. Depth on the best quote and overall depth is decreasing in PPIF concurrently at announcements and on non-announcement days. However, subsequent depth evolves differently afterwards. Following high PPIF at announcements both measures of depth increase in the subsequent two hours interval. This suggests that market participants post more limit orders on the book after resolution of information uncertainty at announcements. Following high PPIF on non-announcement days, however, both measures of depth either drop (in the case of the 2-year note) or remains stable (in the case of the 5- and 10-year notes) afterwards. This suggests that market participants refrain from posting limit orders when the nature of information is relatively uncertain on non-announcement days.

Hidden depth also reacts differently to private information at announcement times and on nonannouncement days. Similar to market depth, hidden depth at the best quote and overall hidden depth on non-announcement days is decreasing in the level of private information concurrently and rises afterwards. However, hidden depth increases with level of private information at announcement times. The result seems to suggest that market participants place more hidden depth when the nature and timing of information arrival is known.

The nature of information arrival also plays an important role in spread. Concurrent spread is negatively related to PPIF in general. It is highest in the highest PPIF group both at announcement times and on non-announcement days. However, spread in a high PPIF group on announcement days reverts subsequently. The intuition is that once information unfolds in announcements, uncertainty quickly resolves in the treasury market. On the other hand, spread in the highest PPIF group on non- 
announcement days remains at around the same level in the subsequent two hours horizon. Thus market participants refrain from posting aggressive quotes when the nature of private information arrival is unknown on non-announcement days.

Volatility varies differently at announcement times and on non-announcement days. Volatility increases with private information level at announcement times. It then drops in the subsequent two hours. This suggests that uncertainty resolves quickly after announcements. However, volatility on non-announcement days exhibits a U-shaped pattern. It is high with both low and high levels of private information. Moreover, subsequent volatility drops only slightly. This suggests that volatility converges slowly after both high and low levels of private information on non-announcement days.

\section{Conclusion}

In this paper, we examine the informativeness of return volatility and order flow impact in the US treasury market. We use a simple Markov switching model and obtain estimates of the probability of information arrival(PPIF) over 5-minute intervals to examine private information on both announcement days and non-announcement days. Results of both a nonparametric test and a probit model show that bond price changes associated with high PPIF exhibit significant permanent price impact over 30 minute, 1-hour and 1-day horizons on both announcement and non-announcement days. Although the impact of PPIF drops overtime, it remains significant up to the 1-day interval.

Consistent with existing studies, our results show that bond price variation is positively related to public information shocks. Liquiidty shocks have a more significant effect on price variation on a non-announcement days. Most importantly, for both announcement and non-announcement days, PPIF has significant explanatory power for bond variance, even after controlling for public information and liquidity shocks.

We also finding interesting relationships between informativeness and subsequent liquidity dynamics. A higher level of private information is associated with lower trading volume, lower depth and lower hidden depth concurrently and at the subsequent two hour horizon, both at the best quote and on the whole book. The difference is more pronounced on non-announcement days. It suggests that 
market participants refrain from trading and posting new limit orders after information arrival. However, information arrival on non-announcement days affects spread differently. Spread in the highest PPIF group on announcement days reverts subsequently after information arrival but spread on nonannouncement days remains at elevated levels. Our findings suggests market participants refrain from posting aggressive quotes for a prolonged period when the nature of information arrival is unknown on non-announcement days. 


\section{References}

Ahn, S., and M. Melvin, 2007, "Exchange Rate and FOMC Days" Journal of Money, Credit and Banking,39(5),1245-1266

Andersen, T. G., 1996, "Return Volatility and Trading Volume: An Information Flow Interpretation of Stochastic Volatility," Journal of Finance, 51(1), 169-204.

Andersen, T., and T. Bollerslev, 1998, “Answering The Skeptics: Yes, Standard Volatility Models Do Provide Accurate Forecasts," International Economic Review,39, 885905

Andersen, T. G., T. Bollerslev, F. X. Diebold, and C. Vega, 2007, "Real-Time Price Discovery in Stock, Bond and Foreign Exchange Markets,” Journal of International Economics, 73, 251-277.

Back, K., Cao, H. and Willard, G., 2000, "Imperfect Competition Among Informed Traders," Journal of Finance, 55(5), 2117-2155.

Balduzzi, P., E. Elton, and C. Green, 2001, "Economic News and Bond Prices: Evidence From the U.S. Treasury Market," Journal of Financial and Quantitative Analysis, 36, 523-543.

Barclay, M., T. Hendershott, and K. Kotz, 2006, “Automation versus Intermediation: Evidence from Treasuries Going Off the Run,” Journal of Finance, 61(5), 2395-2414.

Brandt, T., and K. Kavajecz, 2004, "Price Discovery in the U.S. Treasury Market: The Impact of Order Flow and Liquidity on the Yield Curve" Journal of Finance,59(6), 2623-2654

Clark, B. K., 1973, “A Subordinated Stochastic Process Model with Finite Variance For Speculative Prices," Econometrica, 41, 135-155.

Ederington, L. and J.H. Lee (1993), "How Markets Process Information: News Releases and Volatility, Journal of Finance 48(4), 1161-1189.

Fleming, M. and B. Mizrach, 2008, “The Microstructure of a U.S. Treasury ECN: The BrokerTec Platform," Working paper, Rutgers University.

Fleming, M. and E. Remolona, 1999, "Price Formation and Liquidity in the U.S. Treasury Market: The Response to Public Information,” Journal of Finance, 54(5), 1901-1915. 
Fleming, M. and E. Remolona, 1997, “What Moves the Bond Market?” Federal Reserve Bank of New York Economic Policy Review, 3(4), 31-50

Green, T.C., 2004, "Economic News and the Impact of Trading on Bond Prices," Journal of Finance, 59(3), 1201-1233.

Li, H., J. Wang, C. Wu and Y. He, 2009, "Are Liquidity and Information Risks Priced in the Treasury Bond Market?" Journal of Finance, forthcoming.

Locke, P. and Z. Onayev, 2007, “Order flow, Dealer Profitability, and Price formation,” Journal of Financial Economics, 85, 857-887.

Menkveld, A.J., A. Sarkar and M. van der Wel, 2008, "Customer Flow, Intermediaries and the Discovery of the Equilibrium Riskfree Rate,” Working paper, Federal Reserve Bank of New York.

Mizrach, B. and C. Neely, 2008, "The Microstructure of the U.S. Treasury," The Encyclopedia of Complexity and System Science, New York: Springer-Verlag, forthcoming.

Odders-White, E, and M. Ready, 2008, "The Probability and Magnitude of Information Events," Journal of Financial Economics, 87, 227-248.

Pasquariello, P. and C. Vega, 2007, "Informed and Strategic Order Flow in the Bond Markets," Review of Financial Studies, 20, 1975-2019.

Sager, M. and M. Taylor, 2004, "The impact of European Central Bank Governing Council announcements on the foreign exchange market: a microstructural analysis, " Journal of International Money and Finance,23,1043-1051 


\section{Table 1. Summary Statistics of Market Activities}

This table reports the summary statistics of daily trading volume (\$ billions), daily return volatility (\%) of 5-minute returns based on the mid bid-ask quote from 7:00 a.m. to 5:00 p.m., relative spread $(\times 10,000)$ and spread in ticks, average depth at the best bid and ask (\$ millions), average depth in the entire order book (\$ millions), average hidden depth at the best bid and ask (\$ millions), and average hidden depth in the entire book during the sample period from January 5, 2004 to June 29, 2007. Spread and depth variables are averaged over 5-minute intervals of the trading day.

\begin{tabular}{lccccccc}
\hline Variable & Mean & Median & StDev & Max & Min & Skewness & Kurtosis \\
\hline Panel A: 2-year note & & & & & & & \\
Spread (in ticks) & 0.86 & 0.84 & 0.07 & 1.55 & 0.78 & 3.80 & 25.81 \\
Relative spread ( $\times$ 10,000) & 1.09 & 1.06 & 0.09 & 1.98 & 0.99 & 3.91 & 27.28 \\
Trading volume (\$ billions) & 25.86 & 23.94 & 12.18 & 108.83 & 6.05 & 1.61 & 8.07 \\
Return volatility (\%) & 0.07 & 0.06 & 0.04 & 0.57 & 0.03 & 5.04 & 45.65 \\
Depth at the best bid and ask & 547.09 & 509.98 & 334.78 & 1567.41 & 63.27 & 0.35 & 1.98 \\
Hidden Depth at the best bid and ask & 28.02 & 22.37 & 22.46 & 285.27 & 1.82 & 3.39 & 28.14 \\
Depth of the entire order book & 4092.43 & 3348.95 & 3136.67 & 11980.99 & 145.32 & 0.40 & 1.90 \\
Hidden depth of the entire order book & 70.81 & 54.72 & 61.36 & 561.15 & 3.89 & 2.72 & 14.87 \\
\hline Panel C: 5-year note & & & & & & & \\
Spread (in ticks) & 0.99 & 0.94 & 0.18 & 2.40 & 0.81 & 3.48 & 20.62 \\
Relative spread ( $\times 10,000)$ & 1.26 & 1.18 & 0.22 & 3.02 & 1.03 & 3.45 & 20.20 \\
Trading volume (\$ billions) & 23.43 & 22.05 & 9.50 & 67.81 & 5.65 & 0.99 & 4.63 \\
Return volatility (\%) & 0.18 & 0.16 & 0.10 & 1.66 & 0.06 & 5.98 & 67.36 \\
Depth at the best bid and ask & 107.13 & 107.50 & 51.64 & 237.99 & 20.90 & 0.32 & 2.09 \\
Hidden Depth at the best bid and ask & 6.24 & 5.09 & 4.40 & 39.37 & 0.14 & 1.85 & 9.20 \\
Depth of the entire order book & 1142.62 & 939.02 & 861.82 & 3819.46 & 81.98 & 0.84 & 2.91 \\
Hidden depth of the entire order book & 33.54 & 23.35 & 102.25 & 2883.53 & 1.22 & 26.03 & 723.85 \\
\hline Panel D: 10-year note & & & & & & & \\
Spread (in ticks) & 1.87 & 1.80 & 0.24 & 3.35 & 1.60 & 2.69 & 12.21 \\
Relative spread ( $\times$ 10,000) & 1.18 & 1.13 & 0.15 & 2.14 & 0.99 & 2.72 & 12.51 \\
Trading volume (\$ billions) & 20.70 & 19.82 & 8.94 & 69.64 & 4.14 & 0.85 & 4.67 \\
Return volatility (\%) & 0.30 & 0.28 & 0.15 & 1.92 & 0.11 & 4.48 & 37.74 \\
Depth at the best bid and ask & 108.71 & 108.39 & 49.54 & 243.36 & 16.46 & 0.23 & 2.29 \\
Hidden Depth at the best bid and ask & 5.16 & 4.32 & 3.75 & 30.31 & 0.13 & 2.24 & 11.75 \\
Depth of the entire order book & 1347.02 & 1117.87 & 910.89 & 3739.46 & 81.28 & 0.55 & 2.18 \\
Hidden depth of the entire order book & 31.53 & 25.90 & 26.08 & 257.22 & 1.29 & 3.21 & 21.84 \\
\hline & & & & & & &
\end{tabular}




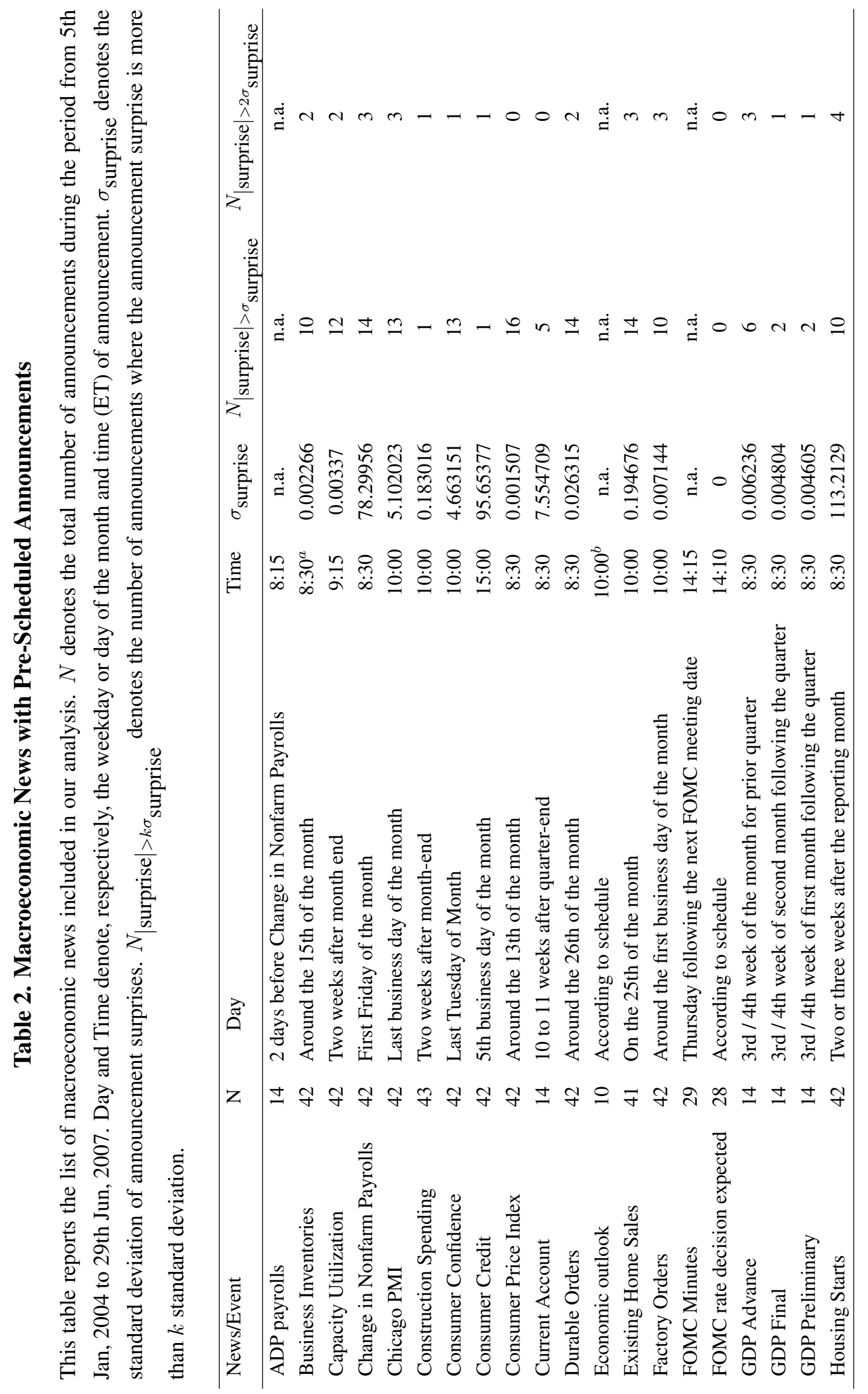




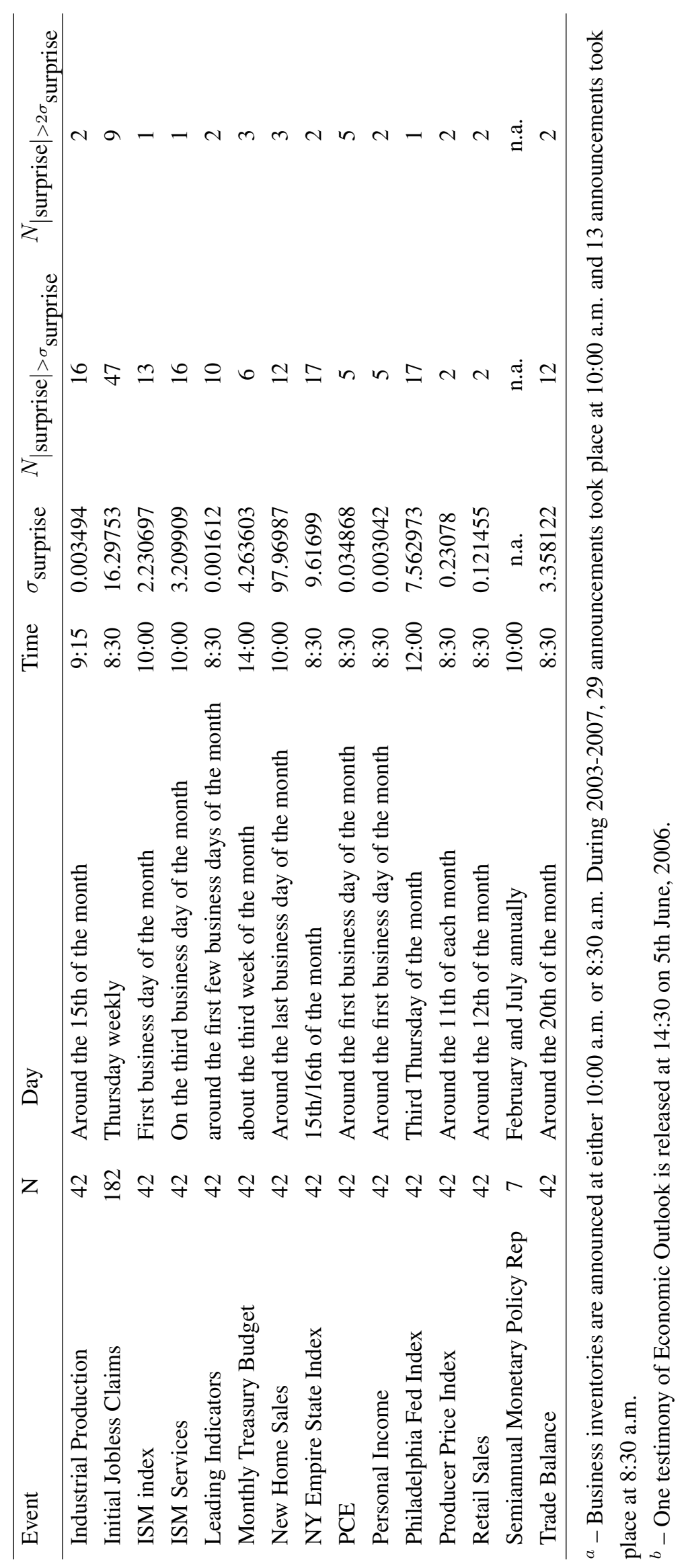




\section{Table 3. Estimation Results of the Markov Switching Model}

This table reports the estimation results of the Markov switching model with state-varying order flow impact

$$
\Delta p_{t}=\rho_{p} \Delta p_{t-1}+\mu_{p}+\mu_{p, P P I F} * S_{t}+\beta_{O F} O F_{t}+\beta_{O F, P P I F} * O F_{t} * S_{t}+\sum_{j=1}^{N} \gamma_{j} S U R_{j t}+\varepsilon_{t}
$$

where $\varepsilon_{t} \sim N\left(0, \sigma+\sum_{j=1}^{N} \theta_{j}\left|S U R_{j, t}\right|\right), S_{t}$ is a latent variable that equals 1 if private information arrives at the market and 0 otherwise. We include standardized announcement surprises $S U R_{j t}$ for the following 12 important news and events (i.e., $N=12$ ): Nonfarm Payroll, Consumer Confidence Index, ISM Index, Initial Jobless Claims, Leading Indicators, New Home Sales, Retail Sales, CPI, Durable Goods Orders, GDP Advance, and PPI. In addition, we set a dummy variable for FOMC. Estimates related to news announcements and events are not reported for brevity.

\begin{tabular}{lccc}
\hline Parameter & 2-year Note & 5-year Note & 10-year Note \\
\hline$\mu$ & 0.010 & 0.044 & 0.058 \\
& $(0.000)$ & $(0.000)$ & $(0.000)$ \\
$\mu_{P P I F}$ & 0.052 & 0.027 & -0.060 \\
$\sigma$ & $(0.050)$ & $(0.256)$ & $(0.779)$ \\
& 0.570 & 1.350 & 2.276 \\
$\beta_{O F}$ & $(0.000)$ & $(0.000)$ & $(0.000)$ \\
& 0.014 & 0.021 & 0.038 \\
$\beta_{O F, P P I F}$ & $(0.000)$ & $(0.000)$ & $(0.000)$ \\
& 0.116 & 0.117 & 0.186 \\
$p_{11}$ & $(0.000)$ & $(0.000)$ & $(0.000)$ \\
& 0.989 & 0.983 & 0.983 \\
$p_{22}$ & $(0.000)$ & $(0.000)$ & $(0.000)$ \\
& 0.418 & 0.704 & 0.718 \\
Announcement Surprises & $(0.000)$ & $(0.000)$ & $(0.000)$ \\
(Included) & $\ldots$ & $\ldots$ & $\ldots$ \\
Likelihood Function & & & \\
\hline
\end{tabular}


Table 4. Summary Statistics of the Probability of Private Information Flow (PPIF)

This table reports the summary statistics of the estimates of the probability of private information flow (PPIF) based on the Markov switch model as in equation (8). The results are based on 5-minute data.

\begin{tabular}{lcccccccccc}
\hline Maturity & Mean & Median & StDev. & Max. & Min. & Skew. & Kurt. & $\rho_{1}$ & $\rho_{2}$ & $\rho_{3}$ \\
\hline Panel A: All Days & & & & & & & & & \\
2-year & 0.019 & 0.009 & 0.071 & 0.042 & 0.000 & 10.796 & 132.818 & 0.396 & 0.224 & 0.163 \\
5-year & 0.049 & 0.019 & 0.121 & 0.187 & 0.000 & 5.385 & 35.629 & 0.635 & 0.480 & 0.393 \\
10-year & 0.051 & 0.020 & 0.120 & 0.200 & 0.000 & 5.242 & 34.352 & 0.653 & 0.497 & 0.411 \\
Panel B: Announcement & Days & & & & & & & & \\
2-year & 0.020 & 0.009 & 0.078 & 0.045 & 0.000 & 9.943 & 111.673 & 0.395 & 0.223 & 0.161 \\
5-year & 0.053 & 0.019 & 0.131 & 0.218 & 0.000 & 5.045 & 31.125 & 0.627 & 0.475 & 0.389 \\
10-year & 0.055 & 0.020 & 0.130 & 0.235 & 0.000 & 4.906 & 29.949 & 0.647 & 0.491 & 0.407 \\
Panel C: Non-announcement Days & & & & & & & & \\
2-year & 0.014 & 0.011 & 0.039 & 0.035 & 0.000 & 15.550 & 317.207 & 0.409 & 0.231 & 0.191 \\
5-year & 0.037 & 0.019 & 0.081 & 0.112 & 0.000 & 6.821 & 61.666 & 0.697 & 0.518 & 0.422 \\
10-year & 0.039 & 0.021 & 0.080 & 0.123 & 0.000 & 6.700 & 60.886 & 0.702 & 0.546 & 0.446 \\
\hline
\end{tabular}




\section{Table 5. Nonparametric Test of Permanent Price Impact}

This table reports the p-values (\%) of the nonparametric test of permanent price impact conditional on high (low) PPIF where high (low) PPIF estimates are defined as above (below) the 33th (66th) percentile of the PPIF estimates over the past 5 days. Details of the nonparametric test can be found in Kaniel and Liu (2006).

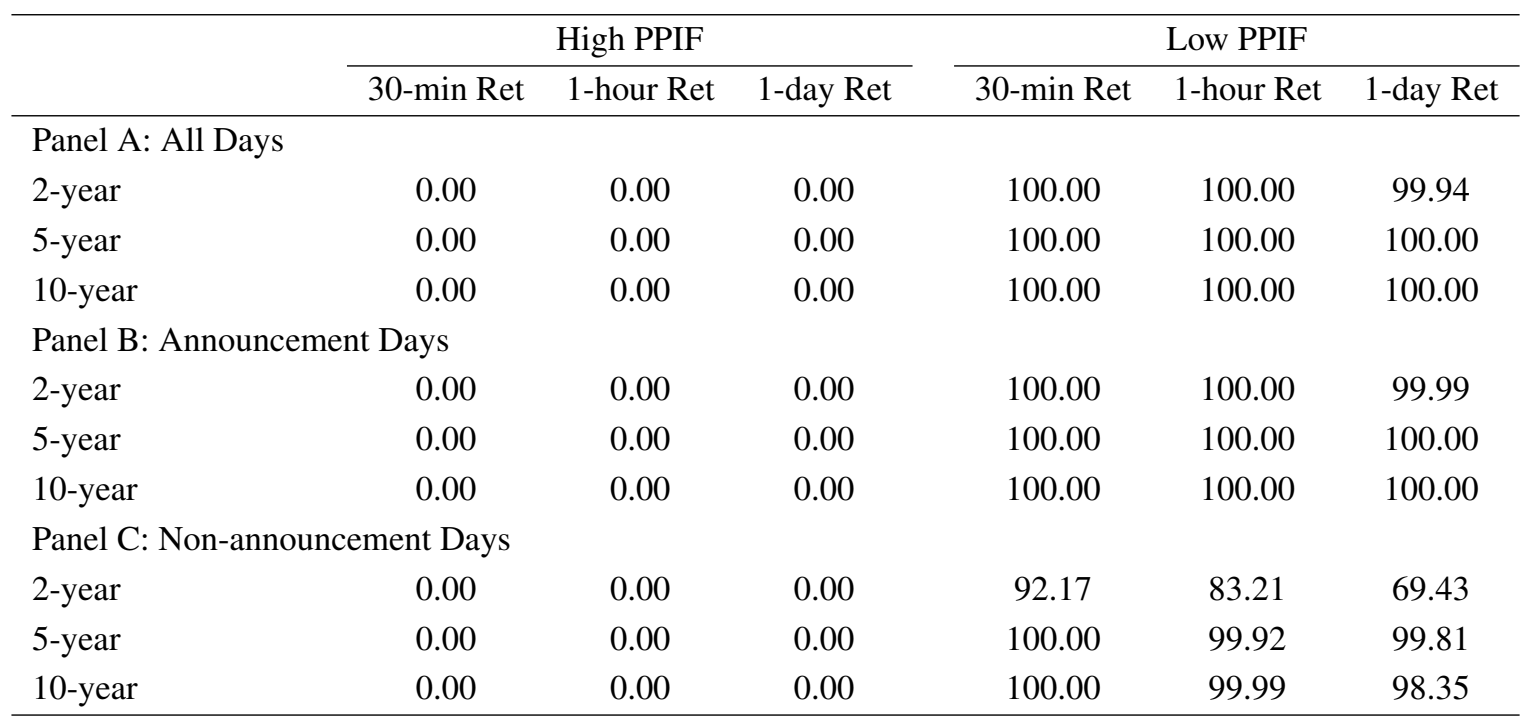




\section{Table 6. Estimation Results of the Probit Model for Permanent Price Impact}

This table reports the estimation result of the probit model that relate the direction of future price change to PPIF estimates. The first column reports the results for all trading days, the second column reports the results for announcement days and the last column reports the results for non-announcement days.

\begin{tabular}{|c|c|c|c|c|c|c|c|c|c|}
\hline & \multicolumn{3}{|c|}{ All Days } & \multicolumn{3}{|c|}{ Announcement days } & \multicolumn{3}{|c|}{ Non-announcement days } \\
\hline & $30 \mathrm{~min}$ & 1 hour & 1 day & $30 \mathrm{~min}$ & 1 hour & 1 day & $30 \min$ & 1 hour & 1 day \\
\hline \multicolumn{10}{|c|}{ Panel A: 2-year note } \\
\hline \multirow[t]{2}{*}{$\alpha$} & -0.552 & -0.587 & -0.667 & -0.524 & -0.558 & -0.642 & -0.691 & -0.746 & -0.761 \\
\hline & $(0.000)$ & $(0.000)$ & $(0.000)$ & $(0.000)$ & $(0.000)$ & $(0.000)$ & $(0.000)$ & $(0.000)$ & $(0.000)$ \\
\hline \multirow[t]{2}{*}{ PPIF } & 2.493 & 2.190 & 1.557 & 2.277 & 1.994 & 1.453 & 6.448 & 6.895 & 2.769 \\
\hline & $(0.000)$ & $(0.000)$ & $(0.000)$ & $(0.000)$ & $(0.000)$ & $(0.000)$ & $(0.000)$ & $(0.000)$ & $(0.000)$ \\
\hline SUR (included) & & & & $\ldots$ & $\cdots$ & $\ldots$ & & & \\
\hline \multicolumn{10}{|l|}{ Likelihood } \\
\hline Function & -38334 & -37648 & -35970 & -29205 & -28740 & -27473 & -9048.0 & -8809.6 & -8446.7 \\
\hline \multicolumn{10}{|c|}{ Panel B: 5-year note } \\
\hline \multirow[t]{2}{*}{$\alpha$} & -0.053 & -0.111 & -0.230 & -0.044 & -0.100 & -0.219 & -0.086 & -0.150 & -0.266 \\
\hline & $(0.000)$ & $(0.000)$ & $(0.000)$ & $(0.000)$ & $(0.000)$ & $(0.000)$ & $(0.000)$ & $(0.000)$ & $(0.000)$ \\
\hline \multirow[t]{2}{*}{ PPIF } & 1.238 & 1.046 & 0.643 & 1.190 & 0.986 & 0.606 & 1.549 & 1.495 & 0.877 \\
\hline & $(0.000)$ & $(0.000)$ & $(0.000)$ & $(0.000)$ & $(0.000)$ & $(0.000)$ & $(0.000)$ & $(0.000)$ & $(0.000)$ \\
\hline SUR (included) & & & & $\cdots$ & $\ldots$ & $\ldots$ & & & \\
\hline \multicolumn{10}{|l|}{ Likelihood } \\
\hline Function & -43020 & -43022 & -42472 & -32404 & -32441 & -32080 & -10605 & -10566 & -10379 \\
\hline \multicolumn{10}{|c|}{ Panel C: 10 -year note } \\
\hline \multirow[t]{2}{*}{$\alpha$} & -0.115 & -0.168 & -0.272 & -0.101 & -0.154 & -0.260 & -0.170 & -0.222 & -0.316 \\
\hline & $(0.000)$ & $(0.000)$ & $(0.000)$ & $(0.000)$ & $(0.000)$ & $(0.000)$ & $(0.000)$ & $(0.000)$ & $(0.000)$ \\
\hline \multirow[t]{2}{*}{ PPIF } & 1.357 & 1.150 & 0.748 & 1.277 & 1.072 & 0.693 & 1.975 & 1.753 & 1.149 \\
\hline & $(0.000)$ & $(0.000)$ & $(0.000)$ & $(0.000)$ & $(0.000)$ & $(0.000)$ & $(0.000)$ & $(0.000)$ & $(0.000)$ \\
\hline SUR (included) & & & & $\ldots$ & $\cdots$ & $\cdots$ & & & \\
\hline \multicolumn{10}{|l|}{ Likelihood } \\
\hline Function & -43006 & -42897 & -42225 & -32633 & -32584 & -32116 & -10352 & -10290 & -10092 \\
\hline
\end{tabular}




\section{Table 7. The Effect of Information Shocks, Liquidity Shocks, and PPIF on Bond Price Variations}

This table reports the estimation results of the regressions of bond return volatility. The explanatory variables include PPIF, liquidity shocks and absolute announcement surprise for two post-announcement period (15-minute horizon, $(0,15]$, and 15- to 30-minute horizon, $(15,30]$, after announcement ), and PPIF and liquidity shocks for pre-announcement period and non-announcement days. The announcements includes Nonfarm Payroll (Nonfarm), Consumer Confidence Index (C.Confi), ISM Index (ISM), Initial Jobless Claims(Ini.Jobls.), Leading Indicators (Leading), New Home Sales (NewHome), Retail Sales (Retail), CPI, Durable Goods (Dur), GDP advance (GDPadv) and PPI.

Panel A: 2-year Note

\begin{tabular}{|c|c|c|c|c|c|c|}
\hline & Pre-Ann. & Post-Ann . $(0,15]$ & Post-Ann . $(0,15]$ & Post-Ann . $(15,30]$ & Post-Ann . $(15,30]$ & Non-Ann. \\
\hline \multirow[t]{2}{*}{$\alpha$} & 0.013 & 0.018 & 0.018 & 0.015 & 0.014 & 0.010 \\
\hline & $(0.000)$ & $(0.000)$ & $(0.000)$ & $(0.000)$ & $(0.000)$ & $(0.000)$ \\
\hline \multirow[t]{2}{*}{ PPIF } & 0.021 & 0.057 & 0.056 & 0.023 & 0.022 & 0.030 \\
\hline & $(0.286)$ & $(0.000)$ & $(0.000)$ & $(0.000)$ & $(0.000)$ & $(0.000)$ \\
\hline \multirow[t]{2}{*}{ DEPALLSHK } & 0.000 & & -0.001 & & -0.000 & -0.000 \\
\hline & $(0.854)$ & & (0.094) & & $(0.000)$ & $(0.152)$ \\
\hline \multirow[t]{2}{*}{ SPRDSHK } & -0.000 & & -0.000 & & -0.000 & 0.000 \\
\hline & $(0.913)$ & & $(0.703)$ & & $(0.091)$ & $(0.117)$ \\
\hline \multirow[t]{2}{*}{ TRDQNSHK } & -0.000 & & -0.000 & & 0.001 & 0.002 \\
\hline & $(0.568)$ & & $(0.537)$ & & $(0.000)$ & $(0.000)$ \\
\hline \multirow[t]{2}{*}{ NonFarm } & & 0.083 & 0.083 & 0.013 & 0.010 & \\
\hline & & $(0.000)$ & $(0.000)$ & $(0.000)$ & $(0.000)$ & \\
\hline \multirow[t]{2}{*}{ C.Confi } & & 0.003 & 0.003 & -0.000 & -0.001 & \\
\hline & & $(0.336)$ & $(0.360)$ & $(0.929)$ & $(0.361)$ & \\
\hline \multirow[t]{2}{*}{ CPI } & & 0.011 & 0.010 & 0.003 & 0.002 & \\
\hline & & $(0.002)$ & $(0.003)$ & $(0.007)$ & $(0.064)$ & \\
\hline \multirow[t]{2}{*}{ Dur } & & 0.003 & 0.003 & 0.001 & 0.001 & \\
\hline & & $(0.275)$ & $(0.243)$ & $(0.302)$ & $(0.307)$ & \\
\hline \multirow[t]{2}{*}{ GDPadv } & & 0.010 & 0.010 & 0.004 & 0.003 & \\
\hline & & $(0.011)$ & $(0.010)$ & $(0.004)$ & $(0.008)$ & \\
\hline \multirow[t]{2}{*}{ ISM } & & 0.005 & 0.005 & 0.001 & 0.001 & \\
\hline & & $(0.100)$ & $(0.101)$ & $(0.163)$ & $(0.475)$ & \\
\hline \multirow[t]{2}{*}{ Ini.Jbls } & & 0.003 & 0.003 & 0.001 & 0.001 & \\
\hline & & $(0.118)$ & $(0.080)$ & $(0.127)$ & $(0.083)$ & \\
\hline \multirow[t]{2}{*}{ Leading } & & -0.002 & -0.001 & -0.002 & -0.002 & \\
\hline & & $(0.558)$ & $(0.629)$ & $(0.034)$ & (0.069) & \\
\hline \multirow[t]{2}{*}{ NewHome } & & 0.003 & 0.003 & 0.002 & 0.001 & \\
\hline & & $(0.363)$ & $(0.345)$ & $(0.063)$ & $(0.217)$ & \\
\hline \multirow[t]{2}{*}{ PPI } & & -0.000 & -0.000 & -0.000 & -0.001 & \\
\hline & & $(0.895)$ & $(0.908)$ & $(0.616)$ & (0.118) & \\
\hline \multirow[t]{2}{*}{ Retail } & & 0.003 & 0.003 & -0.000 & -0.000 & \\
\hline & & $(0.496)$ & $(0.506)$ & $(0.723)$ & $(0.841)$ & \\
\hline Adj. $R^{2}$ & -0.0063 & 0.5556 & 0.5558 & 0.2578 & 0.3790 & 0.2361 \\
\hline
\end{tabular}


Panel B: 5-year Note

\begin{tabular}{|c|c|c|c|c|c|c|}
\hline & Pre-Ann. & Post-Ann . $(0,15]$ & Post-Ann . $(0,15]$ & Post-Ann . $(15,30]$ & Post-Ann . $(15,30]$ & Non-Ann. \\
\hline \multirow[t]{2}{*}{$\alpha$} & 0.026 & 0.039 & 0.040 & 0.032 & 0.030 & 0.021 \\
\hline & $(0.000)$ & $(0.000)$ & $(0.000)$ & $(0.000)$ & $(0.000)$ & $(0.000)$ \\
\hline \multirow[t]{2}{*}{ PPIF } & 0.025 & 0.099 & 0.101 & 0.051 & 0.047 & 0.047 \\
\hline & $(0.050)$ & $(0.000)$ & $(0.000)$ & $(0.000)$ & $(0.000)$ & $(0.000)$ \\
\hline \multirow[t]{2}{*}{ DEPALLSHK } & 0.001 & & 0.001 & & -0.000 & -0.000 \\
\hline & $(0.018)$ & & $(0.489)$ & & $(0.380)$ & $(0.000)$ \\
\hline \multirow[t]{2}{*}{ SPRDSHK } & 0.000 & & 0.000 & & -0.000 & -0.000 \\
\hline & $(0.825)$ & & $(0.159)$ & & $(0.552)$ & $(0.968)$ \\
\hline \multirow[t]{2}{*}{ TRDQNSHK } & -0.000 & & -0.001 & & 0.001 & 0.003 \\
\hline & $(0.861)$ & & $(0.241)$ & & $(0.000)$ & $(0.000)$ \\
\hline \multirow[t]{2}{*}{ NonFarm } & & 0.228 & 0.231 & 0.034 & 0.027 & \\
\hline & & $(0.000)$ & $(0.000)$ & $(0.000)$ & $(0.000)$ & \\
\hline \multirow[t]{2}{*}{ C.Confi } & & 0.004 & 0.005 & 0.001 & 0.000 & \\
\hline & & $(0.640)$ & $(0.556)$ & $(0.739)$ & $(0.854)$ & \\
\hline \multirow[t]{2}{*}{ CPI } & & 0.023 & 0.024 & 0.010 & 0.008 & \\
\hline & & $(0.011)$ & $(0.007)$ & $(0.000)$ & $(0.001)$ & \\
\hline \multirow[t]{2}{*}{ Dur } & & 0.009 & 0.010 & 0.001 & 0.001 & \\
\hline & & $(0.253)$ & $(0.191)$ & $(0.602)$ & $(0.794)$ & \\
\hline \multirow[t]{2}{*}{ GDPadv } & & 0.019 & 0.020 & 0.009 & 0.008 & \\
\hline & & $(0.078)$ & (0.059) & $(0.002)$ & $(0.006)$ & \\
\hline \multirow[t]{2}{*}{ ISM } & & 0.013 & 0.015 & 0.004 & 0.003 & \\
\hline & & $(0.123)$ & $(0.076)$ & $(0.068)$ & (0.194) & \\
\hline \multirow[t]{2}{*}{ Ini.Jbls } & & 0.005 & 0.005 & 0.002 & 0.002 & \\
\hline & & $(0.244)$ & $(0.237)$ & $(0.071)$ & $(0.074)$ & \\
\hline \multirow[t]{2}{*}{ Leading } & & -0.007 & -0.007 & -0.003 & -0.002 & \\
\hline & & $(0.385)$ & $(0.383)$ & (0.104) & $(0.223)$ & \\
\hline \multirow[t]{2}{*}{ NewHome } & & 0.006 & 0.006 & 0.004 & 0.004 & \\
\hline & & $(0.464)$ & $(0.420)$ & (0.109) & $(0.098)$ & \\
\hline \multirow[t]{2}{*}{ PPI } & & -0.002 & -0.002 & -0.001 & -0.001 & \\
\hline & & $(0.767)$ & $(0.792)$ & $(0.756)$ & $(0.481)$ & \\
\hline \multirow[t]{2}{*}{ Retail } & & 0.020 & 0.019 & -0.006 & -0.005 & \\
\hline & & $(0.081)$ & $(0.085)$ & $(0.064)$ & $(0.074)$ & \\
\hline Adj. $R^{2}$ & 0.0168 & 0.5492 & 0.5501 & 0.3898 & 0.4383 & 0.2484 \\
\hline
\end{tabular}


Panel C: 10-year Note

\begin{tabular}{|c|c|c|c|c|c|c|}
\hline & Pre-Ann. & Post-Ann . $(0,15]$ & Post-Ann . $(0,15]$ & Post-Ann . $(15,30]$ & Post-Ann . $(15,30]$ & Non-Ann. \\
\hline \multirow[t]{2}{*}{$\alpha$} & 0.045 & 0.070 & 0.062 & 0.057 & 0.052 & 0.038 \\
\hline & $(0.000)$ & $(0.000)$ & $(0.000)$ & $(0.000)$ & $(0.000)$ & $(0.000)$ \\
\hline \multirow[t]{2}{*}{ PPIF } & 0.021 & 0.100 & 0.088 & 0.069 & 0.065 & 0.081 \\
\hline & $(0.178)$ & $(0.000)$ & $(0.000)$ & $(0.000)$ & $(0.000)$ & $(0.000)$ \\
\hline \multirow[t]{2}{*}{ DEPALLSHK } & -0.000 & & -0.001 & & -0.001 & -0.001 \\
\hline & $(0.818)$ & & $(0.597)$ & & $(0.000)$ & $(0.000)$ \\
\hline \multirow[t]{2}{*}{ SPRDSHK } & 0.000 & & 0.000 & & -0.000 & 0.000 \\
\hline & $(0.953)$ & & $(0.718)$ & & $(0.147)$ & $(0.059)$ \\
\hline \multirow[t]{2}{*}{ TRDQNSHK } & 0.000 & & 0.002 & & 0.002 & 0.005 \\
\hline & $(0.254)$ & & $(0.000)$ & & $(0.000)$ & $(0.000)$ \\
\hline \multirow[t]{2}{*}{ NonFarm } & & 0.294 & 0.277 & 0.049 & 0.036 & \\
\hline & & $(0.000)$ & $(0.000)$ & $(0.000)$ & $(0.000)$ & \\
\hline \multirow[t]{2}{*}{ C.Confi } & & 0.008 & 0.005 & 0.003 & 0.002 & \\
\hline & & $(0.457)$ & $(0.649)$ & $(0.400)$ & $(0.536)$ & \\
\hline \multirow[t]{2}{*}{ CPI } & & 0.041 & 0.030 & 0.013 & 0.009 & \\
\hline & & $(0.000)$ & $(0.011)$ & $(0.002)$ & $(0.018)$ & \\
\hline \multirow[t]{2}{*}{ Dur } & & 0.011 & 0.005 & 0.001 & -0.000 & \\
\hline & & $(0.264)$ & $(0.628)$ & $(0.807)$ & $(0.971)$ & \\
\hline \multirow[t]{2}{*}{ GDPadv } & & 0.041 & 0.036 & 0.016 & 0.014 & \\
\hline & & $(0.003)$ & $(0.007)$ & $(0.001)$ & $(0.003)$ & \\
\hline \multirow[t]{2}{*}{ ISM } & & 0.022 & 0.013 & 0.006 & 0.003 & \\
\hline & & $(0.047)$ & $(0.251)$ & $(0.120)$ & $(0.401)$ & \\
\hline \multirow[t]{2}{*}{ Ini.Jbls } & & 0.007 & 0.007 & 0.004 & 0.004 & \\
\hline & & $(0.186)$ & $(0.233)$ & $(0.039)$ & $(0.029)$ & \\
\hline \multirow[t]{2}{*}{ Leading } & & -0.012 & -0.008 & -0.005 & -0.003 & \\
\hline & & $(0.221)$ & $(0.390)$ & $(0.121)$ & $(0.369)$ & \\
\hline \multirow[t]{2}{*}{ NewHome } & & 0.000 & -0.001 & 0.002 & 0.004 & \\
\hline & & (0.993) & $(0.944)$ & $(0.520)$ & $(0.293)$ & \\
\hline \multirow[t]{2}{*}{ PPI } & & 0.001 & 0.001 & -0.000 & -0.000 & \\
\hline & & $(0.872)$ & $(0.902)$ & (0.997) & $(0.931)$ & \\
\hline \multirow[t]{2}{*}{ Retail } & & 0.013 & 0.008 & -0.007 & -0.006 & \\
\hline & & $(0.369)$ & $(0.580)$ & $(0.196)$ & $(0.227)$ & \\
\hline Adj. $R^{2}$ & 0.0000 & 0.5354 & 0.5494 & 0.3050 & 0.4110 & 0.2719 \\
\hline
\end{tabular}




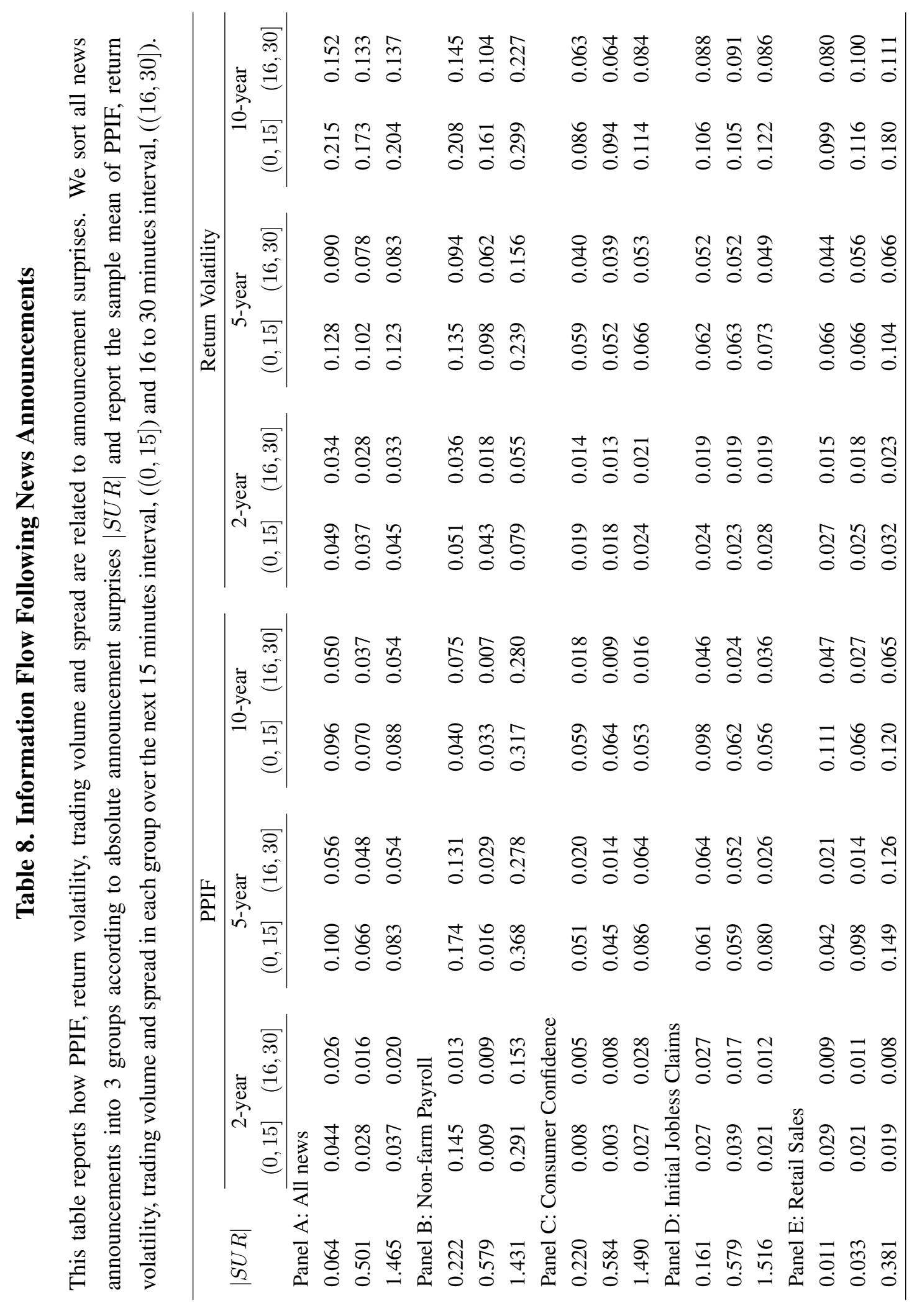




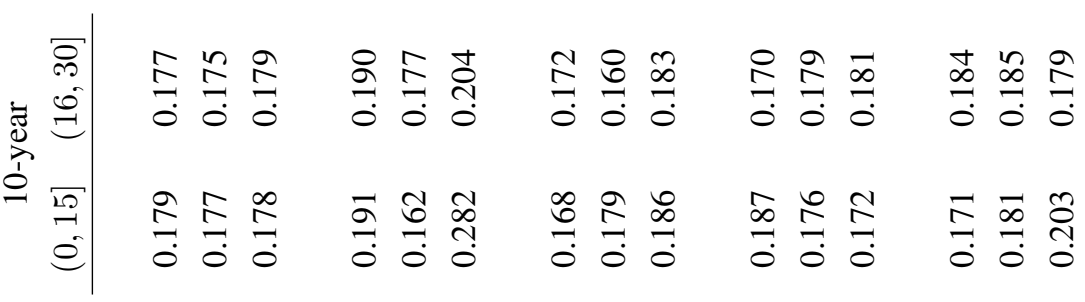

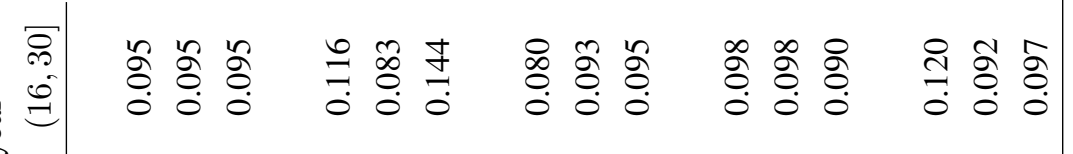

ตั้

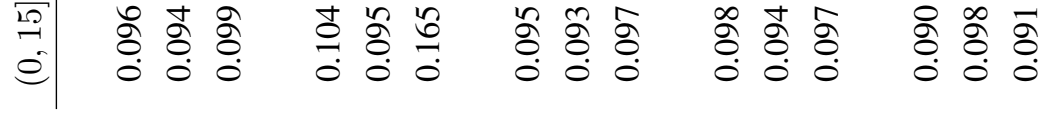

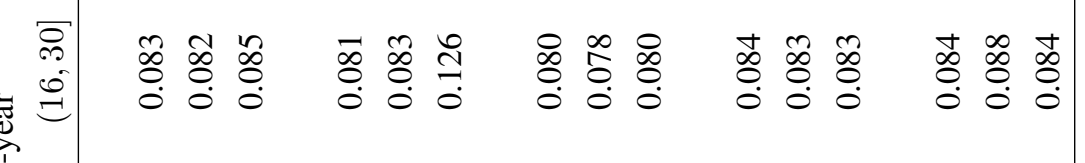

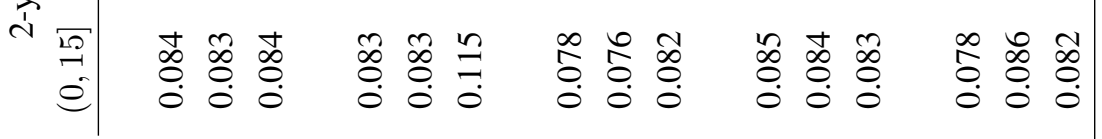

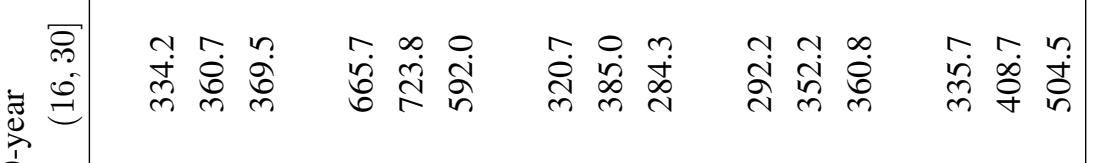

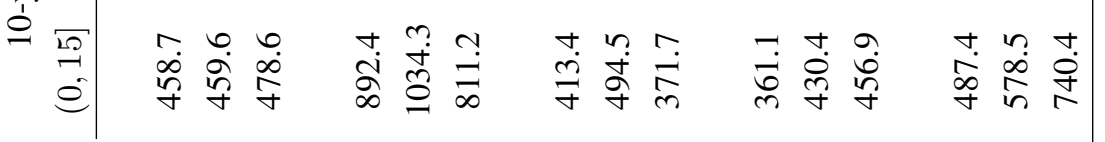

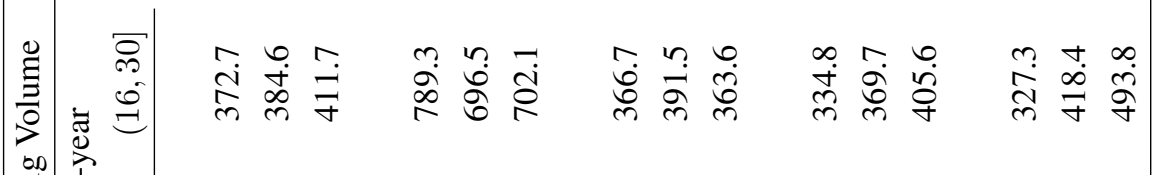

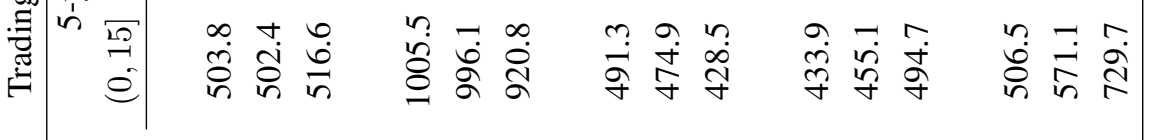

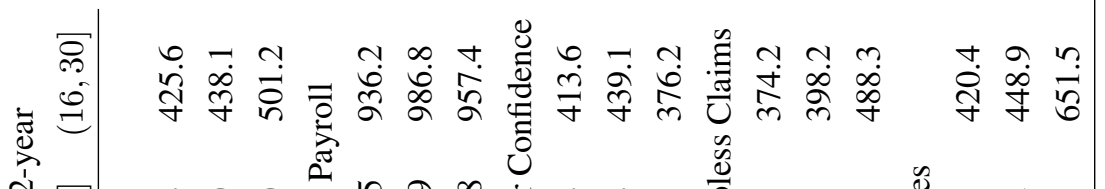

芳岛

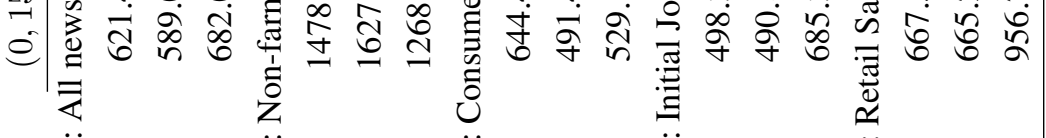

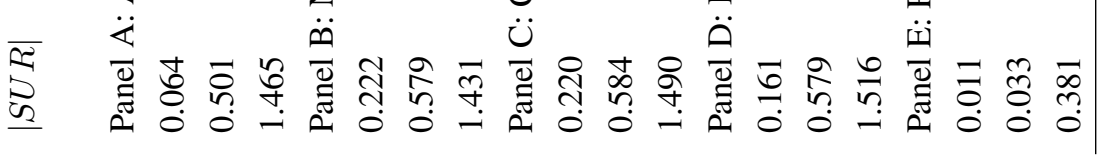




\section{Table 9. Relation between PPIF, Volatility and Liquidity Variables}

The table reports how liquidity is related to PPIF. On announcement days, we sort PPIF at announcements into 3 equal groups. On non-announcement days, we sort PPIF at each 5-minute interval into 3 equal groups . For each group, we report the average of depth at the best quotes (DEP0), overall depth (DEPALL), hidden depth at the best quotes (HID0), overall hidden depth (HIDALL), trading volume (TRDQN), relative bid-ask spread (SPREAD), and volatility (VOLATILITY) at the same time interval (denoted by $(-5,0]$ ). We then calculate the averages of these variables within each tercile group in the next 30-minutes interval $(0,30], 30$ - to 60- minutes interval $(30,60], 60$ - to 90 - minutes interval $(60,90]$, and 90 - to 120 - minutes interval $(60,120]$. We use $8: 30$ announcements which are not followed by 10:00 announcements to get cleaner results (i.e. $(-5,0]$ represents the 5-minute interval before an 8:30 announcement). On non-announcement days, data from 8:00a.m. till 3:00p.m. are used.

Panel A: 2-year note

\begin{tabular}{|c|c|c|c|c|c|c|c|c|c|c|c|}
\hline \multicolumn{6}{|c|}{ Post-Announcement Period } & \multicolumn{6}{|c|}{ Non-announcement Days } \\
\hline PPIF & $(-5,0]$ & $(0,30]$ & $(30,60]$ & $(60,90]$ & $(90,120]$ & PPIF & $(-5,0]$ & $(0,30]$ & $(30,60]$ & $(60,90]$ & $(90,120]$ \\
\hline \multicolumn{12}{|c|}{ A.1. TRDQN } \\
\hline 0.0002 & 1190.8 & 565.3 & 363.7 & 351.7 & 321.2 & 0.0003 & 372.3 & 243.6 & 224.2 & 208.6 & 196.5 \\
\hline 0.0091 & 1059.9 & 522.5 & 354.9 & 302.5 & 319.5 & 0.0083 & 136.2 & 195.3 & 194.5 & 182.0 & 169.8 \\
\hline 0.2509 & 978.5 & 572.2 & 360.5 & 334.6 & 281.5 & 0.0280 & 102.5 & 171.6 & 173.6 & 165.9 & 151.7 \\
\hline \multicolumn{12}{|c|}{ A.2. DEP0 } \\
\hline 0.0002 & 542.4 & 714.1 & 780.0 & 729.1 & 767.5 & 0.0003 & 737.9 & 765.5 & 762.7 & 744.1 & 721.6 \\
\hline 0.0091 & 471.7 & 630.8 & 710.9 & 749.4 & 733.7 & 0.0083 & 681.1 & 674.7 & 666.7 & 649.4 & 627.0 \\
\hline 0.2509 & 343.1 & 459.0 & 505.5 & 516.2 & 499.8 & 0.0280 & 614.9 & 603.6 & 592.3 & 571.6 & 547.9 \\
\hline \multicolumn{12}{|c|}{ A.3. DEPALL } \\
\hline 0.0002 & 4911.1 & 5756.3 & 6152.4 & 5896.8 & 6136.3 & 0.0003 & 6017.3 & 6058.4 & 5971.1 & 5768.3 & 5535.1 \\
\hline 0.0091 & 4150.3 & 4878.4 & 5255.8 & 5248.2 & 5370.1 & 0.0083 & 5198.9 & 5170.3 & 5057.4 & 4853.0 & 4602.2 \\
\hline 0.2509 & 2865.1 & 3514.6 & 3824.5 & 3792.5 & 3805.4 & 0.0280 & 4597.9 & 4567.6 & 4424.4 & 4187.8 & 3923.5 \\
\hline \multicolumn{12}{|c|}{ A.4. HID0 } \\
\hline 0.0002 & 3.1 & 11.4 & 17.0 & 22.7 & 14.0 & 0.0003 & 20.2 & 25.8 & 27.1 & 30.9 & 34.8 \\
\hline 0.0091 & 4.4 & 7.7 & 15.0 & 19.8 & 18.8 & 0.0083 & 27.3 & 27.9 & 27.9 & 30.6 & 34.6 \\
\hline 0.2509 & 8.9 & 11.5 & 13.8 & 16.9 & 11.4 & 0.0280 & 29.4 & 27.0 & 30.2 & 32.4 & 35.2 \\
\hline \multicolumn{12}{|c|}{ A.5. HIDALL } \\
\hline 0.0002 & 35.1 & 43.3 & 56.7 & 61.1 & 45.0 & 0.0003 & 72.2 & 76.6 & 78.4 & 83.1 & 87.9 \\
\hline 0.0091 & 37.9 & 65.9 & 72.6 & 77.1 & 68.3 & 0.0083 & 68.5 & 71.1 & 72.3 & 75.3 & 79.8 \\
\hline 0.2509 & 43.1 & 41.7 & 48.4 & 54.8 & 50.8 & 0.0280 & 67.8 & 67.1 & 71.4 & 73.5 & 75.9 \\
\hline \multicolumn{12}{|c|}{ A.6. SPREAD } \\
\hline 0.0002 & 0.083 & 0.082 & 0.082 & 0.081 & 0.082 & 0.0003 & 0.082 & 0.083 & 0.082 & 0.082 & 0.082 \\
\hline 0.0091 & 0.083 & 0.085 & 0.082 & 0.084 & 0.082 & 0.0083 & 0.081 & 0.083 & 0.083 & 0.083 & 0.083 \\
\hline 0.2509 & 0.086 & 0.084 & 0.083 & 0.081 & 0.082 & 0.0280 & 0.082 & 0.083 & 0.083 & 0.083 & 0.083 \\
\hline \multicolumn{12}{|c|}{ A.6. VOLATILITY } \\
\hline 0.0002 & 0.198 & 0.077 & 0.046 & 0.047 & 0.042 & 0.0003 & 0.043 & 0.036 & 0.034 & 0.032 & 0.030 \\
\hline 0.0091 & 0.225 & 0.073 & 0.046 & 0.046 & 0.042 & 0.0083 & 0.022 & 0.033 & 0.032 & 0.031 & 0.029 \\
\hline 0.2509 & 0.441 & 0.085 & 0.056 & 0.056 & 0.051 & 0.0280 & 0.038 & 0.032 & 0.031 & 0.030 & 0.028 \\
\hline
\end{tabular}


Panel B: 5-year note

\begin{tabular}{|c|c|c|c|c|c|c|c|c|c|c|c|}
\hline \multicolumn{6}{|c|}{ Post-Announcement Period } & \multicolumn{6}{|c|}{ Non-announcement Days } \\
\hline PPIF & $(-5,0]$ & $(0,30]$ & $(30,60]$ & $(60,90]$ & $(90,120]$ & PPIF & $(-5,0]$ & $(0,30]$ & $(30,60]$ & $(60,90]$ & $(90,120]$ \\
\hline \multicolumn{12}{|c|}{ B.1. TRDQN } \\
\hline 0.0019 & 814.6 & 471.8 & 342.4 & 346.1 & 328.7 & 0.0011 & 309.3 & 258.1 & 244.9 & 228.3 & 210.1 \\
\hline 0.0259 & 659.1 & 425.3 & 333.2 & 282.0 & 281.1 & 0.0150 & 179.4 & 205.9 & 205.2 & 194.6 & 181.2 \\
\hline 0.4542 & 731.5 & 454.7 & 308.9 & 309.4 & 271.3 & 0.0705 & 141.2 & 168.1 & 167.3 & 159.7 & 147.6 \\
\hline \multicolumn{12}{|c|}{ B.2. DEP0 } \\
\hline 0.0019 & 102.6 & 130.6 & 152.7 & 144.5 & 152.9 & 0.0011 & 149.3 & 150.2 & 150.2 & 148.0 & 144.5 \\
\hline 0.0259 & 93.3 & 109.0 & 113.1 & 112.4 & 114.4 & 0.0150 & 136.8 & 136.8 & 136.1 & 134.2 & 130.1 \\
\hline 0.4542 & 73.1 & 88.4 & 105.8 & 98.6 & 103.5 & 0.0705 & 93.9 & 95.9 & 97.7 & 96.0 & 93.8 \\
\hline \multicolumn{12}{|c|}{ B.3. DEPALL } \\
\hline 0.0019 & 1433.1 & 1675.3 & 1839.3 & 1794.4 & 1903.0 & 0.0011 & 1885.3 & 1889.2 & 1859.0 & 1795.9 & 1724.1 \\
\hline 0.0259 & 1017.8 & 1184.4 & 1266.3 & 1264.1 & 1286.7 & 0.0150 & 1646.3 & 1643.4 & 1609.3 & 1544.5 & 1470.0 \\
\hline 0.4542 & 734.9 & 902.9 & 1026.5 & 1016.1 & 1041.4 & 0.0705 & 988.6 & 1001.8 & 994.7 & 954.3 & 899.6 \\
\hline \multicolumn{12}{|c|}{ B.4. HID0 } \\
\hline 0.0019 & 0.0 & 2.1 & 3.0 & 3.0 & 3.3 & 0.0011 & 5.1 & 5.3 & 6.0 & 7.1 & 7.6 \\
\hline 0.0259 & 0.0 & 2.1 & 2.8 & 4.5 & 3.0 & 0.0150 & 6.0 & 5.9 & 6.2 & 7.2 & 8.1 \\
\hline 0.4542 & 1.0 & 1.2 & 3.5 & 3.3 & 4.3 & 0.0705 & 4.8 & 5.3 & 5.6 & 6.1 & 7.1 \\
\hline \multicolumn{12}{|c|}{ B.5. HIDALL } \\
\hline 0.0019 & 12.8 & 22.3 & 24.0 & 21.0 & 20.5 & 0.0011 & 33.7 & 35.1 & 37.1 & 39.4 & 40.0 \\
\hline 0.0259 & 13.3 & 20.1 & 24.2 & 27.3 & 28.1 & 0.0150 & 33.2 & 34.2 & 35.3 & 37.1 & 39.0 \\
\hline 0.4542 & 18.9 & 20.7 & 16.7 & 22.1 & 30.0 & 0.0705 & 29.9 & 31.5 & 33.9 & 34.4 & 36.4 \\
\hline \multicolumn{12}{|c|}{ B.6. SPREAD } \\
\hline 0.0019 & 0.092 & 0.092 & 0.092 & 0.093 & 0.091 & 0.0011 & 0.090 & 0.090 & 0.090 & 0.090 & 0.090 \\
\hline 0.0259 & 0.095 & 0.097 & 0.092 & 0.094 & 0.091 & 0.0150 & 0.090 & 0.091 & 0.091 & 0.091 & 0.091 \\
\hline 0.4542 & 0.110 & 0.105 & 0.101 & 0.102 & 0.099 & 0.0705 & 0.096 & 0.095 & 0.095 & 0.095 & 0.095 \\
\hline \multicolumn{12}{|c|}{ B.7. VOLATILITY } \\
\hline 0.0019 & 0.574 & 0.190 & 0.125 & 0.138 & 0.112 & 0.0011 & 0.105 & 0.095 & 0.091 & 0.087 & 0.081 \\
\hline 0.0259 & 0.539 & 0.206 & 0.138 & 0.126 & 0.132 & 0.0150 & 0.072 & 0.092 & 0.089 & 0.084 & 0.080 \\
\hline 0.4542 & 0.951 & 0.248 & 0.164 & 0.160 & 0.150 & 0.0705 & 0.119 & 0.104 & 0.099 & 0.095 & 0.090 \\
\hline
\end{tabular}


Panel C: 10-year note

\begin{tabular}{|c|c|c|c|c|c|c|c|c|c|c|c|}
\hline \multicolumn{6}{|c|}{ Post-Announcement Period } & \multicolumn{6}{|c|}{ Non-announcement Days } \\
\hline PPIF & $(-5,0]$ & $(0,30]$ & $(30,60]$ & $(60,90]$ & $(90,120]$ & PPIF & $(-5,0]$ & $(0,30]$ & $(30,60]$ & $(60,90]$ & $(90,120]$ \\
\hline \multicolumn{12}{|c|}{ C.1. TRDQN } \\
\hline 0.0007 & 788.0 & 441.0 & 331.7 & 301.2 & 308.0 & 0.0015 & 278.7 & 233.2 & 218.0 & 204.0 & 186.3 \\
\hline 0.0193 & 632.4 & 373.7 & 280.8 & 270.5 & 273.4 & 0.0175 & 147.1 & 172.5 & 171.9 & 161.8 & 153.1 \\
\hline 0.4527 & 704.3 & 423.4 & 283.0 & 287.1 & 244.4 & 0.0783 & 114.5 & 133.6 & 136.3 & 133.8 & 124.1 \\
\hline \multicolumn{12}{|c|}{ C.2. DEP0 } \\
\hline 0.0007 & 107.8 & 127.0 & 143.7 & 141.5 & 144.2 & 0.0015 & 148.8 & 149.7 & 149.5 & 147.8 & 145.2 \\
\hline 0.0193 & 104.5 & 125.0 & 130.8 & 137.5 & 135.0 & 0.0175 & 128.5 & 130.5 & 130.3 & 128.8 & 126.4 \\
\hline 0.4527 & 77.1 & 95.9 & 103.4 & 99.4 & 106.9 & 0.0783 & 94.6 & 93.2 & 94.8 & 94.7 & 93.7 \\
\hline \multicolumn{12}{|c|}{ C.3. DEPALL } \\
\hline 0.0007 & 1564.8 & 1855.9 & 2068.0 & 2022.1 & 2124.7 & 0.0015 & 2212.6 & 2222.9 & 2187.5 & 2111.4 & 2020.7 \\
\hline 0.0193 & 1420.3 & 1657.9 & 1758.5 & 1748.4 & 1795.4 & 0.0175 & 1831.4 & 1823.4 & 1778.1 & 1697.5 & 1604.7 \\
\hline 0.4527 & 966.6 & 1251.4 & 1390.6 & 1408.5 & 1427.0 & 0.0783 & 1138.5 & 1147.1 & 1125.1 & 1072.6 & 1012.1 \\
\hline \multicolumn{12}{|c|}{ C.4. HID0 } \\
\hline 0.0007 & 0.6 & 2.3 & 2.5 & 3.7 & 3.5 & 0.0015 & 4.8 & 4.8 & 5.0 & 6.1 & 6.3 \\
\hline 0.0193 & 0.3 & 2.1 & 2.5 & 2.4 & 3.1 & 0.0175 & 4.9 & 5.0 & 5.2 & 5.7 & 6.5 \\
\hline 0.4527 & 0.6 & 1.4 & 1.7 & 2.3 & 2.3 & 0.0783 & 3.5 & 3.7 & 4.2 & 4.6 & 5.1 \\
\hline \multicolumn{12}{|c|}{ C.5. HIDALL } \\
\hline 0.0007 & 10.9 & 18.4 & 25.3 & 33.1 & 33.5 & 0.0015 & 39.5 & 40.6 & 42.2 & 43.7 & 44.6 \\
\hline 0.0193 & 8.0 & 15.3 & 21.2 & 17.7 & 22.0 & 0.0175 & 34.6 & 35.3 & 37.2 & 40.2 & 42.9 \\
\hline 0.4527 & 12.5 & 17.7 & 21.6 & 23.5 & 27.1 & 0.0783 & 24.4 & 25.9 & 28.8 & 31.0 & 31.7 \\
\hline \multicolumn{12}{|c|}{ C.6. SPREAD } \\
\hline 0.0007 & 0.185 & 0.180 & 0.183 & 0.179 & 0.173 & 0.0015 & 0.174 & 0.174 & 0.175 & 0.174 & 0.174 \\
\hline 0.0193 & 0.187 & 0.177 & 0.178 & 0.181 & 0.178 & 0.0175 & 0.177 & 0.177 & 0.177 & 0.178 & 0.178 \\
\hline 0.4527 & 0.191 & 0.191 & 0.179 & 0.179 & 0.180 & 0.0783 & 0.185 & 0.184 & 0.184 & 0.184 & 0.185 \\
\hline \multicolumn{12}{|c|}{ C.7. VOLATILITY } \\
\hline 0.0007 & 0.971 & 0.336 & 0.250 & 0.224 & 0.215 & 0.0015 & 0.181 & 0.170 & 0.162 & 0.155 & 0.145 \\
\hline 0.0193 & 0.866 & 0.328 & 0.229 & 0.232 & 0.223 & 0.0175 & 0.129 & 0.161 & 0.154 & 0.147 & 0.140 \\
\hline 0.4527 & 1.836 & 0.420 & 0.257 & 0.259 & 0.248 & 0.0783 & 0.205 & 0.175 & 0.169 & 0.162 & 0.154 \\
\hline
\end{tabular}


FIGURE 1

\section{Intraday Market Activities}

This figure plots market activities in each half-hour window during the day from 7:30 to 17:00. Variables include trading volume ( $\$$ millions), trading duration (seconds), relative bid-ask spread $(\times 10,000)$, return volatility $(\%)$ calculated from 5-minute returns based on the mid bid-ask quote and average depth at the best bid/ask ( $\$$ millions) calculated over each 5-minute interval.

Trading Volume

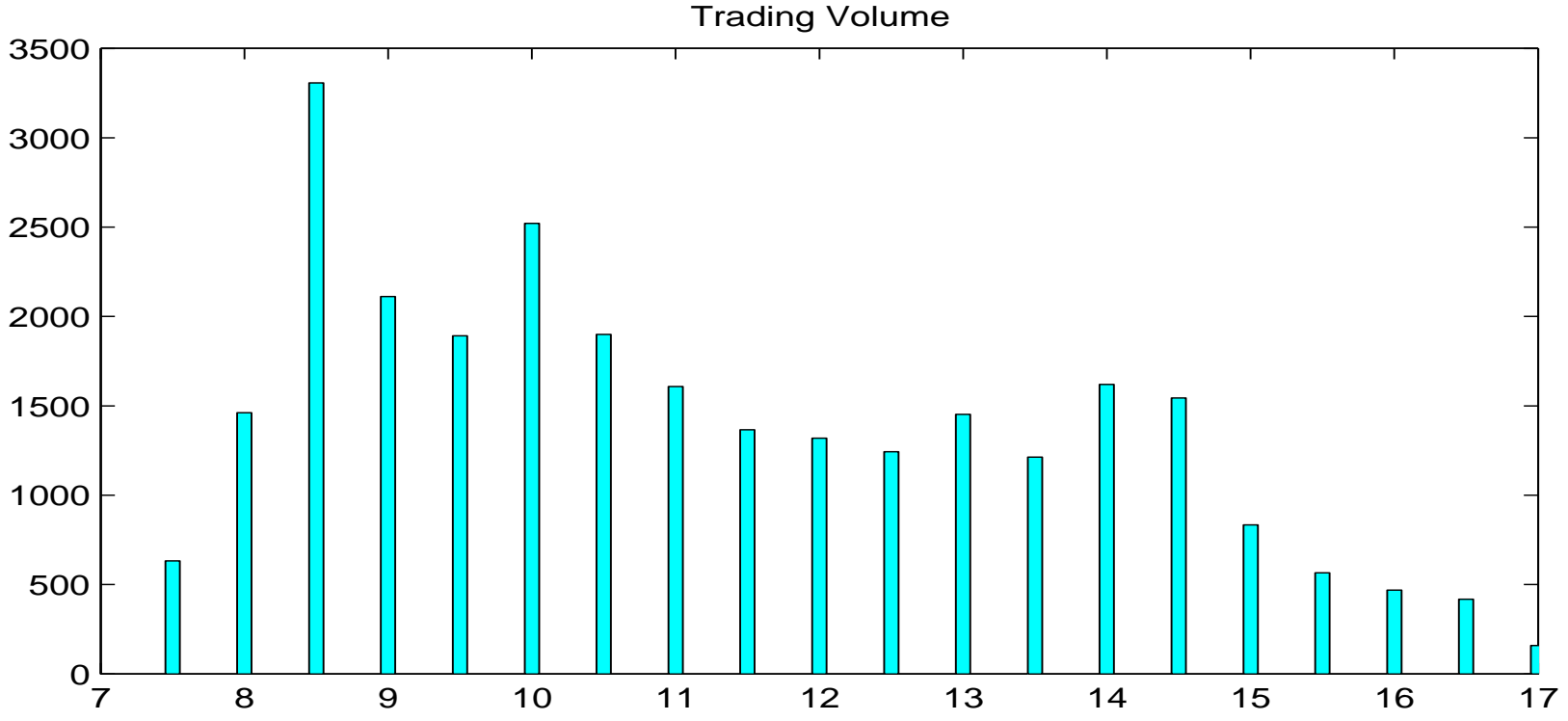

Relative Spread

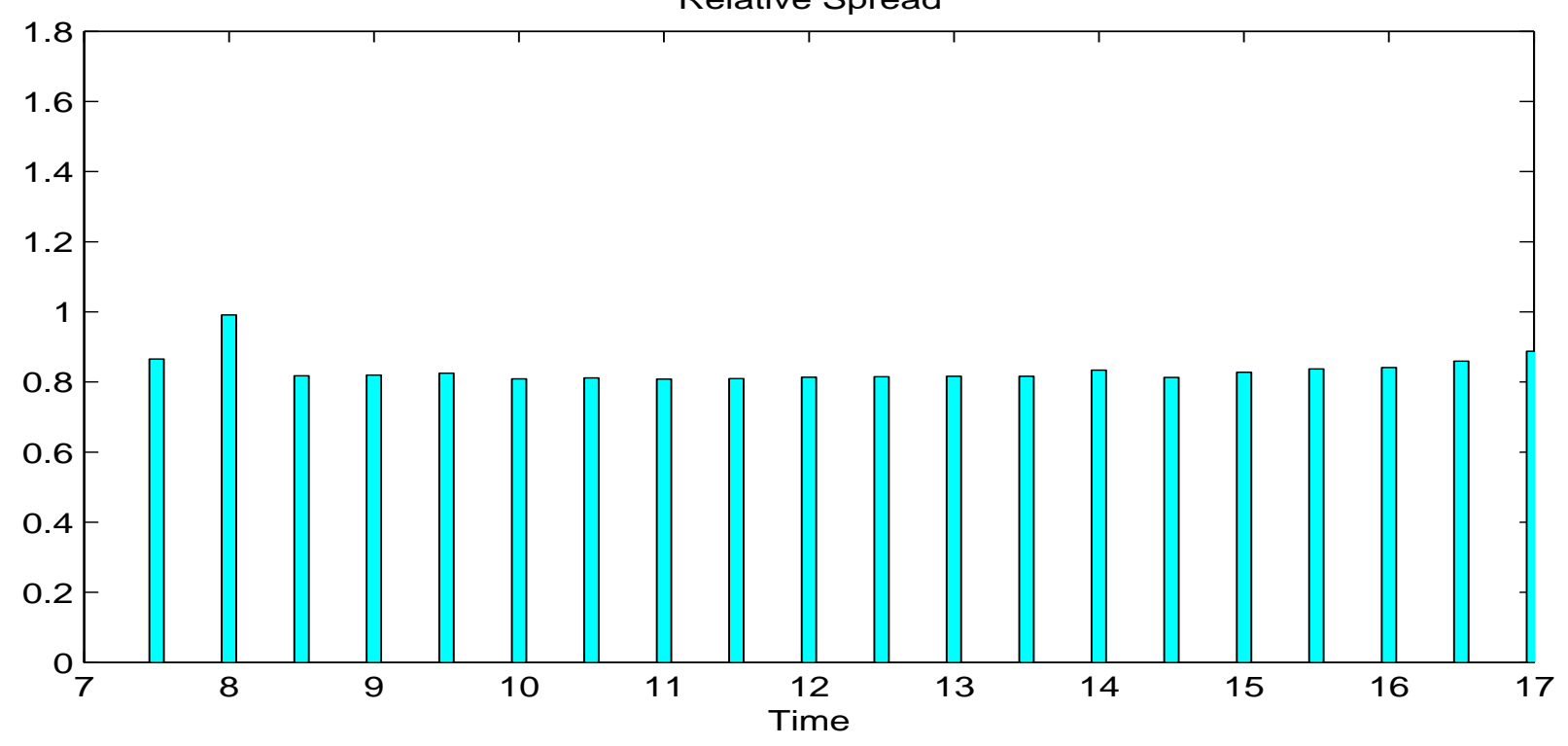




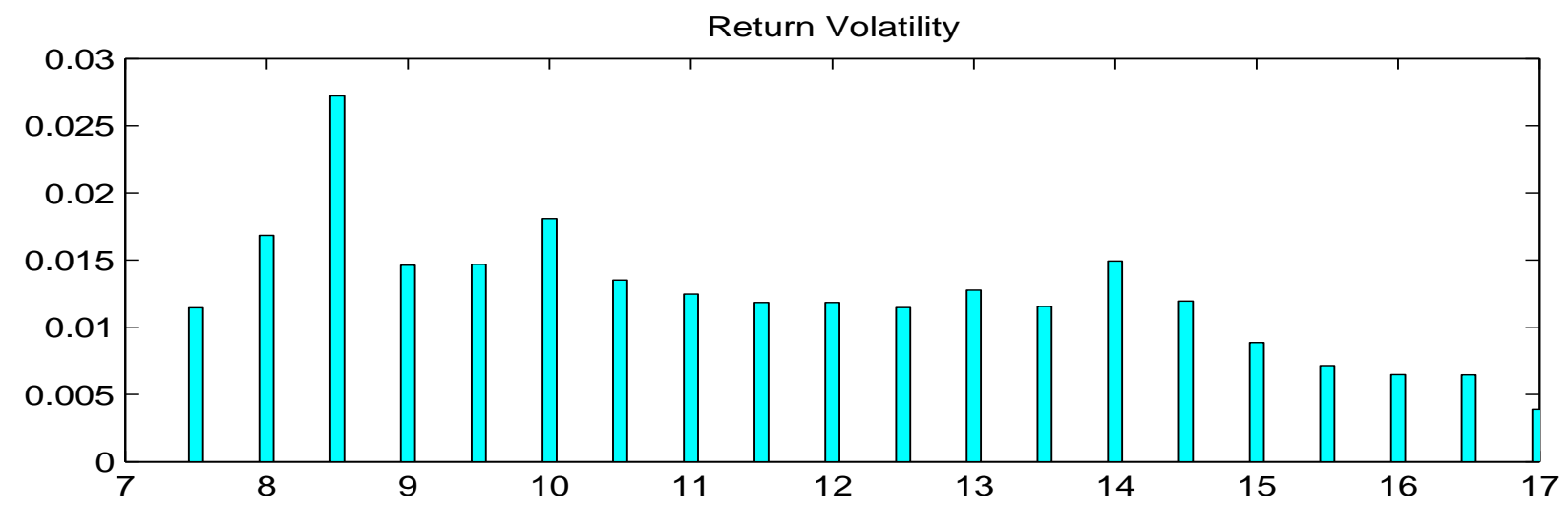

Depth at Best Bid/Ask

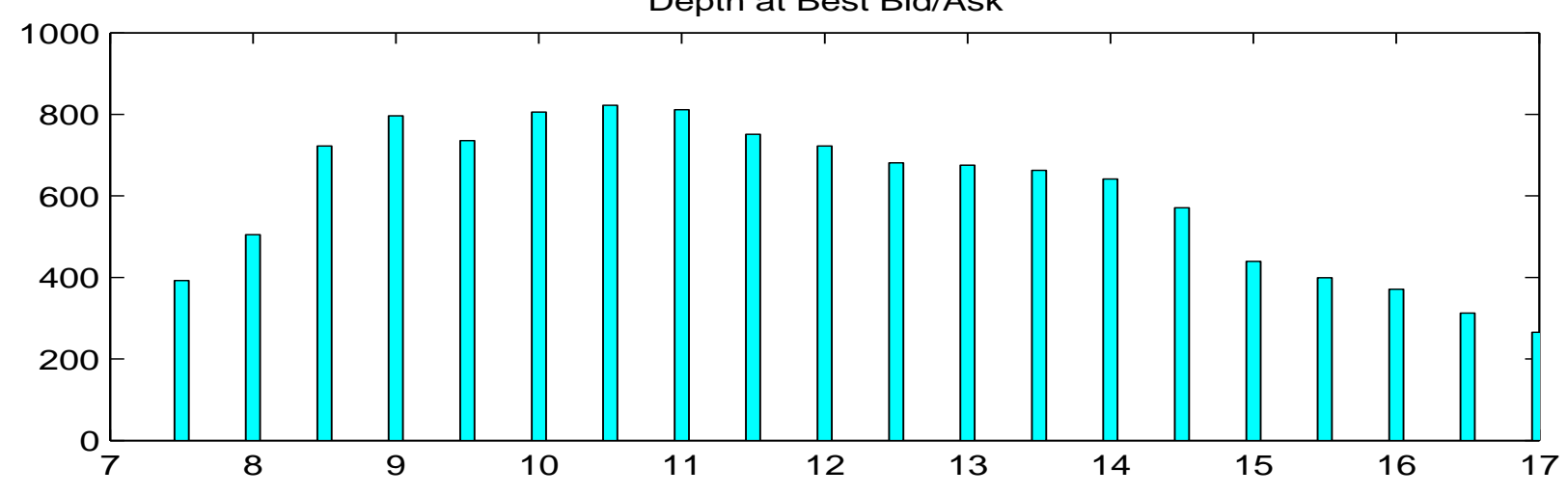

Hidden Depth at Best Bid/Ask

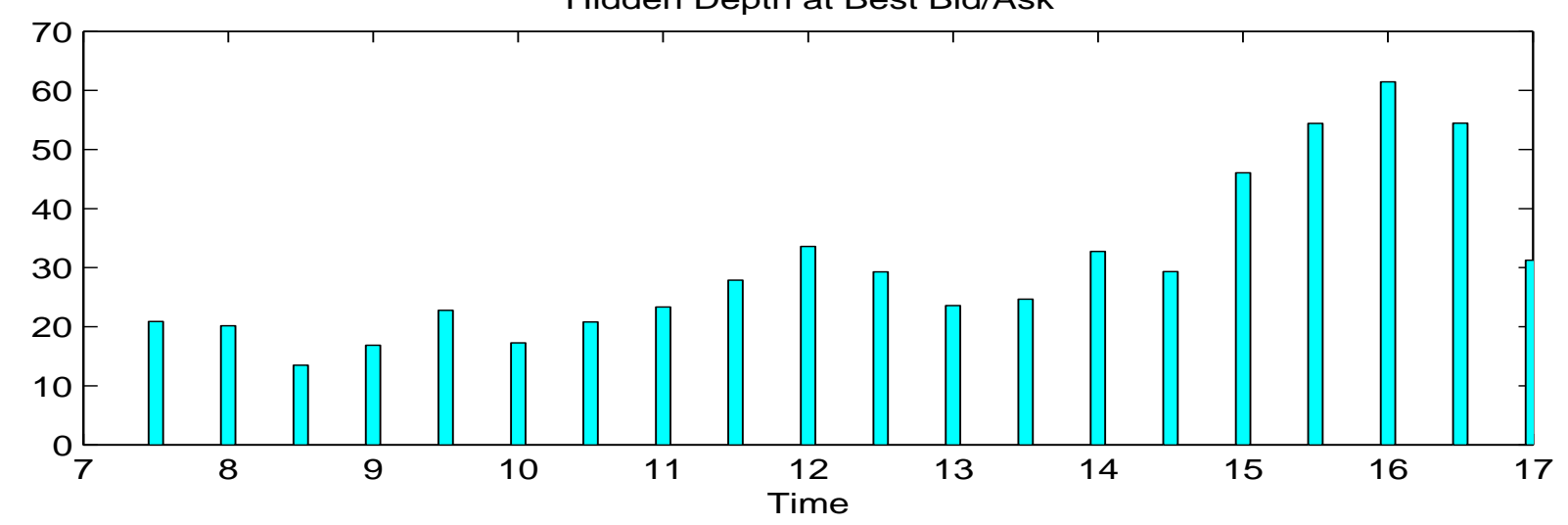


FIGURE 2

\section{Intraday Plots of PPIF}

This figure plots the average estimates $P P I F_{O F I M}$ for the 2-year note in each 5-minute interval during the trading day from 7:30 to 17:00, based on the combined model of return volatility and order flow impact in (??). The intraday patterns are plotted for (a) all days in the sample, (b) days with announcements and (c) days without announcements.

Days with Announcement

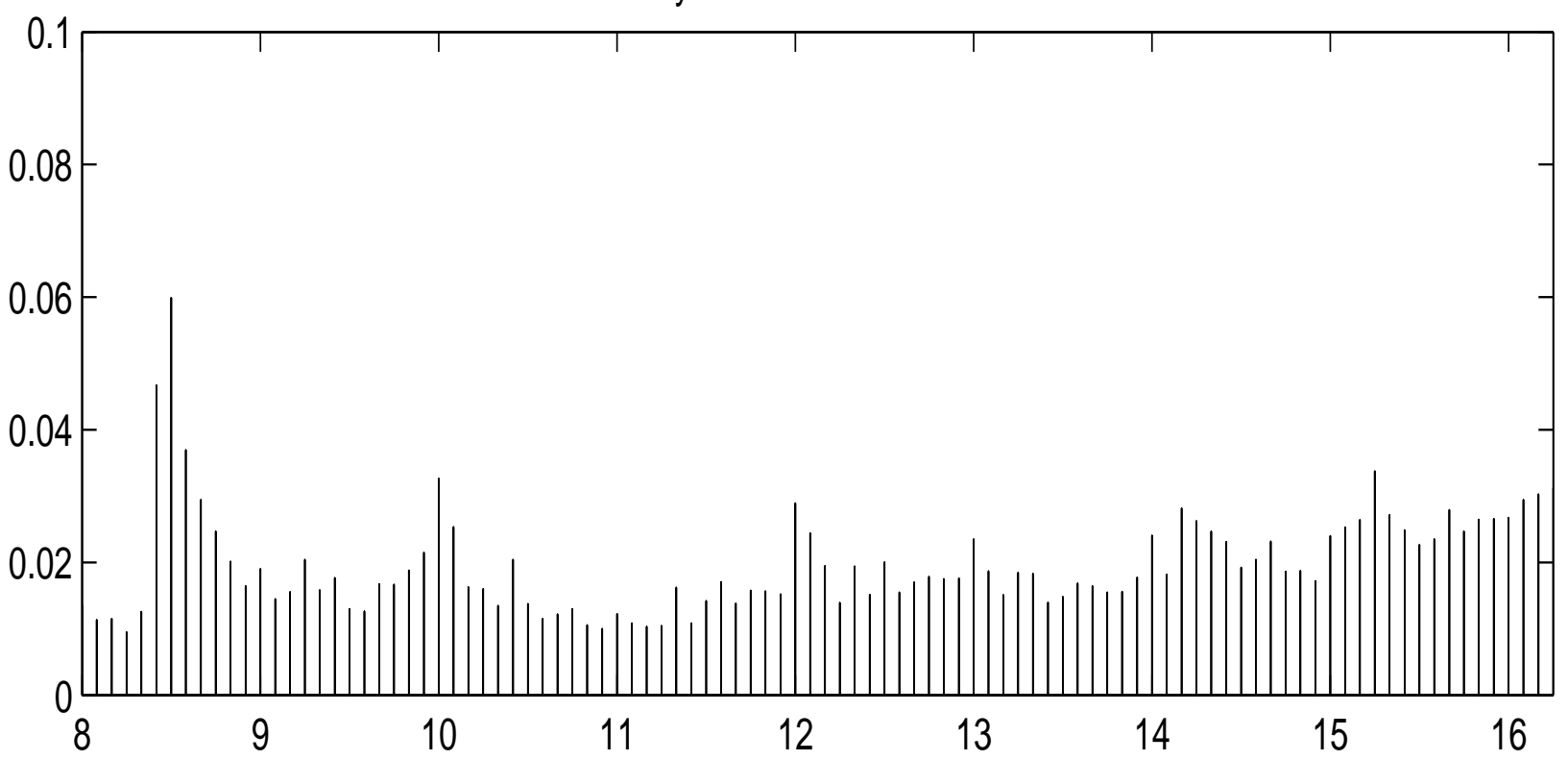

Days without Announcement

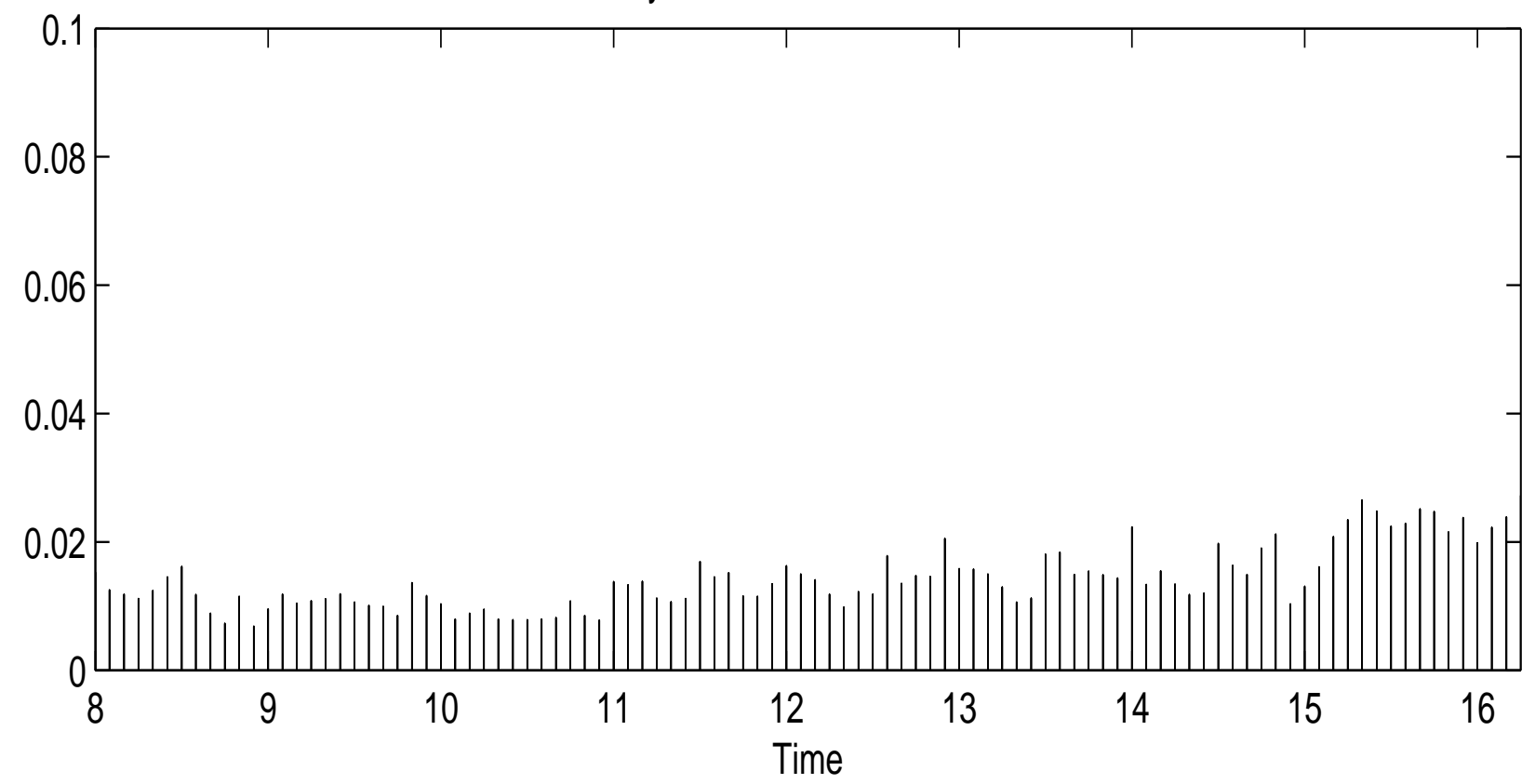

